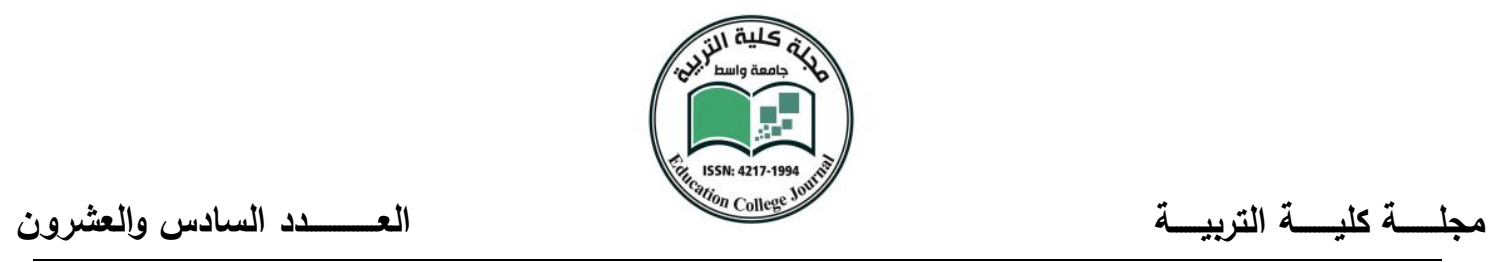

\title{
هيدرجيوكيميائية المياه الجوفية في قضاء العزيزية
}

م.د استبرق كاظم شبوط المسعودي

جامعة واسط / كلية التربية

: المستخلصن

تتاول البحث دراسة نوعية المياه الجوفية للآبارفي قضاء العزيزية في محافظة واسط، وبحسب معادلة كورولوف ( Kurolov Formala) بينت الدراسة أن النوع الكيمياوي لمياه الآبار هو (Sulfat water type).

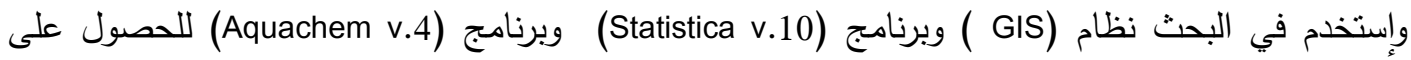
نتائج في منطقة الدراسة.كما نتاول البحث مخطط كَبس (Gibbs diagram) الذي يستخدم على نطاق واسع لدراسة العلاقة بين نكوين المياه الجوفية والخصائص الصخارية الذي بين أن التركيز الكيميائي للمياه الجوفية يقع ضمن سيادة التبخر والصخور • وتم تتاول تقييم نوعية المياه للاغراض المختلفة وعند مقارنتها بالمحددات العراقية والعالمية إتضح عدم صلاحية مياه الآبار للإستخدام البشري،كما أُستخدم ايضاً معايير عالمية لمعرفة مدى صلاحيتها لأغراض الري والمتمنلة بنسبة إمنزاز الصوديوم(SAR) والنسبة المئوية للصوديوم(Na\%) ، كما أُستخدم مخطط ريتشارد ( Richard,1954) ،وتم رسم خرائط نوضح التوزيع المكاني للصفات النوعية لمياه الآبار حيث بينت الدراسة صلاحية مياه الآبار للإستخدام الزراعي عند مقارنتها بالمحددات العراقية والعالمية.

\section{$\underline{\text { Abstract }}$}

The research study of water quality of groundwater Aparfai Azizia spend in Wasit province, according to Korolev equation (Kurolov Formala) study showed that the type of chemical to water wells is (Sulfat water type). Was used in the search system (GIS) and software ((Statistica v.10 program (Aquachem v.4) to get results in Aldrash.kma area touched on CBS scheme (Gibbs diagram) which is used widely to study the relationship between groundwater and characteristics lethlogy which formation between the chemical concentration of groundwater it falls within the sovereignty of evaporation and rocks 
Were addressed water quality assessment for various purposes, and when compared to the Iraqi and international Determinants turned out to be water wells validity for human use, also used global standards to determine their suitability for irrigation and represented by sodium adsorption (SAR) and the percentage of sodium (Na\%), also used by Richard scheme ( Richard, 1954), has been drawing maps showing the spatial distribution of quality recipes for water wells where the study showed the validity of water wells for agricultural use when compared to the Iraqi and international determinants.

المقدمة:

يُعد الماء الجزء المكمل للحياة وأساس إستمرارها ، ومع التغيرات البيئية والمناخية التي تأثرت بملوثات

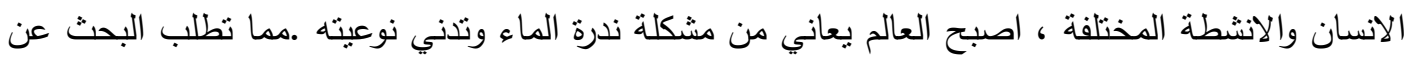

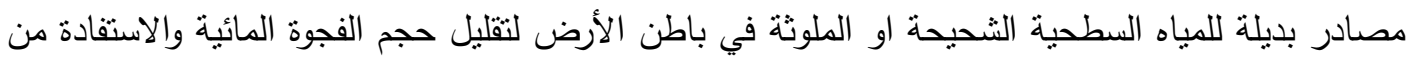
المياه المخزونة كبديل ضروري للمياه السطحية التي باتت لاتسد حاجة الانسان مع مختلف الانشطة اليومية الئية

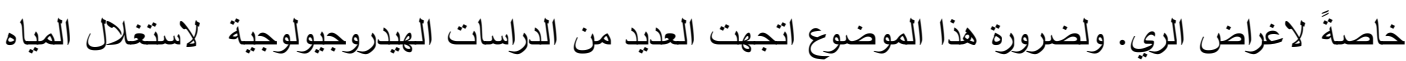

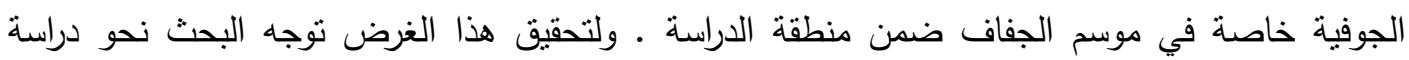
هيدروكيميائية المياه الجوفية لتقيم مدى صلاحية المياه من خلال استخدام تقينيات حديثة وتحاليل كيمبائية لتعطي صور واضحة لنوع المياه ومدى إمكانية الاعتماد عليه كحل بديل للمياه السطحية.

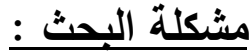

تمثلت مشكلة الدراسة بالأسئلة التالية .

- هل تُعد المياه الجوفية صالحة للاستخدام البشري من خلال تحليل العناصر الكيميائية للمياه ؟

- ما مدى اعتماد سكان قضاء العزيزية على المياه الجوفية في الاستخدامات المختلفة ؟

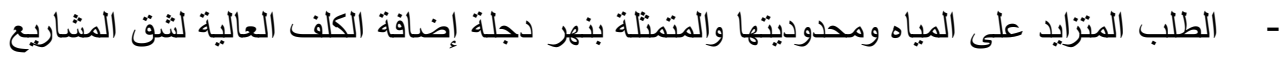
الإروائية ، جعل من الضروري البحث عن مصادر اخرى للمياه؟ 
- - تاثز المياه الجوفية في المنطقة بارتفاع نسبة الأملاح الناتجة من التكوين الجيولوجي للمنطقة .

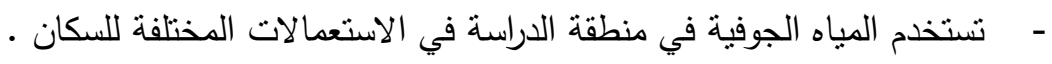
- ل لاتتكل المياه الجوفية أهمية في منطقة الدراسة لوجود المياه السطحية التي تغطي حاجة السكن من

\section{هدف البحث: :}

تهدف الدراسة لتحليل المياه الجوفية ومعرفة تراكيز العناصر الكيميائية والكثف عن مدى صلاحية المياه للإستخدامات المختلفة من خلال جمع العينات من تلك الآبار ، وإستخدام الطرق الإحصائية المناسبة وتحليل خرائط التوزيع المكاني للآبار •

\section{موقع منطقة الاراسة:-}

تتمثل الحدود المكانية لمنطقة الدراسة بقضاء العزبزية والمتمثلة بدائرتي عرض ( $33^{\circ} 2000$ "

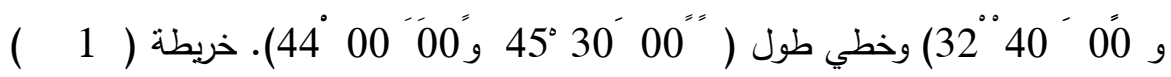




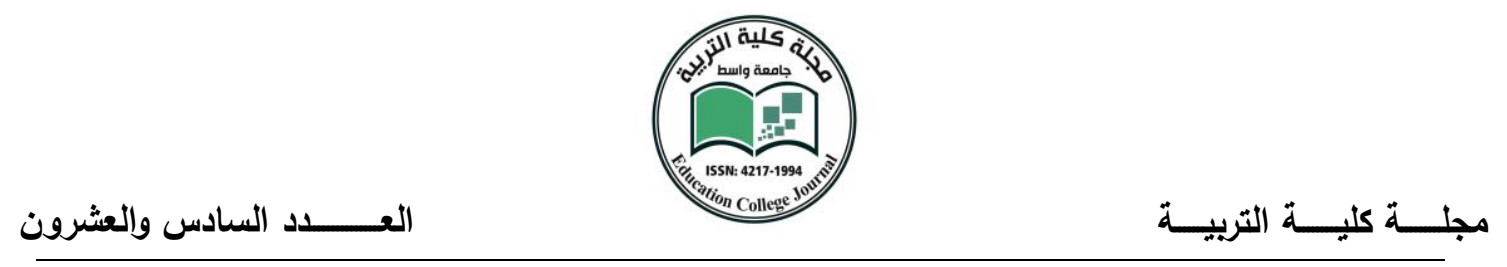

خريطة ( 1 ) موقع منطقة الاراسة

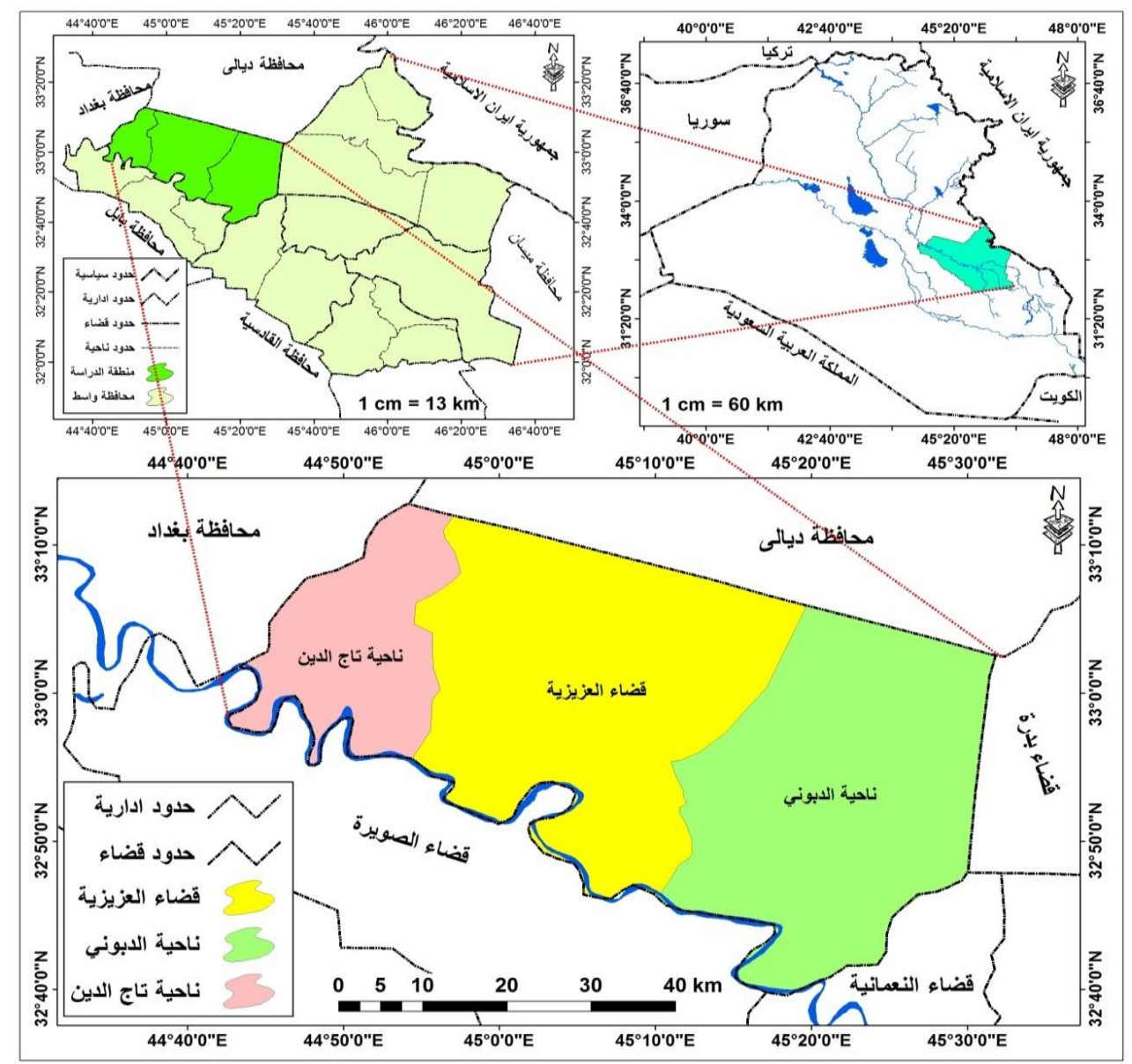

المصدر: الباحث بالاعتماد على1 ASTER DEM DATA ويرنامج (Arc Gis.v.10. 2) 20 20لهيأة العامة للمساحة،خريطة العراق الادارية،مقياس 1 / 1 / 
قام الباحث بالدراسة الميدانية التي تُعد من المراحل المهمة في مرحلة الدراسة، وتم اختيار ( 12) بئراً لجمع عينات المياه تنتوزع جغرافياً على حدود منطقة الدراسة ، وأن تحديد مواقع اللآبار تم بأستخدام جهاز (GPS) لتحديدها على الخربطة وفق الإحداثيات الجغرافية. خربطة ( 2 )

\section{التركيب الجيولوجي:-}

للبنية الجيولوجية دورُ مهٌُ في تحديد كمية الجوفية ونوعيتها التي تشمل الخزانات الموجودة في الصخور بأنواعها وذللك لأن توزيع الصخور وتكوينها يؤثز على الخصائص الكيميائية للمياه الجوفية (القره غولي،2014 صن 212

تقع منطقة الدراسة في الرصيف الغير مستقر ، ضمن صفيحة السهل الفيضي المتمثلة بإلتواء مقعر كبير الأمر الذي ساعد على تجمع الترسبات الطينية والرملية. إذ تغطي ترسبات العصر الرباعي معظم أجزاء

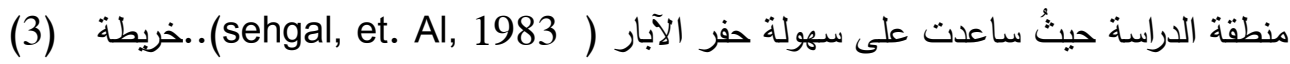


خريطة ( 2 ) مواقع الابارفي منطقة الاراسة

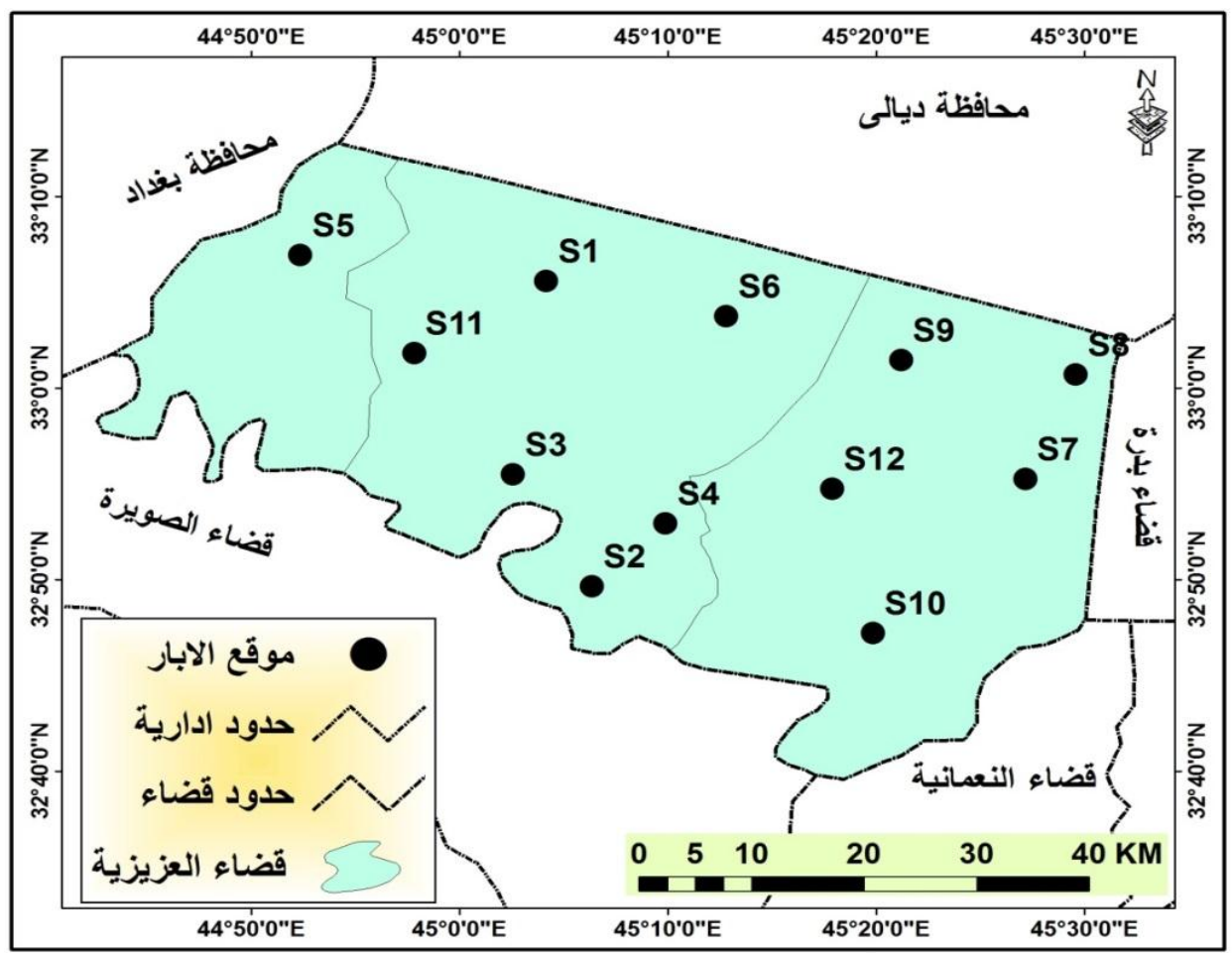

المصدر :- من عمل الباحث بالاعتماد ا-الخريطة الادارية لمحافظة واسط بمقياس2014, 1/250000. 2- جهاز ( (GPS 


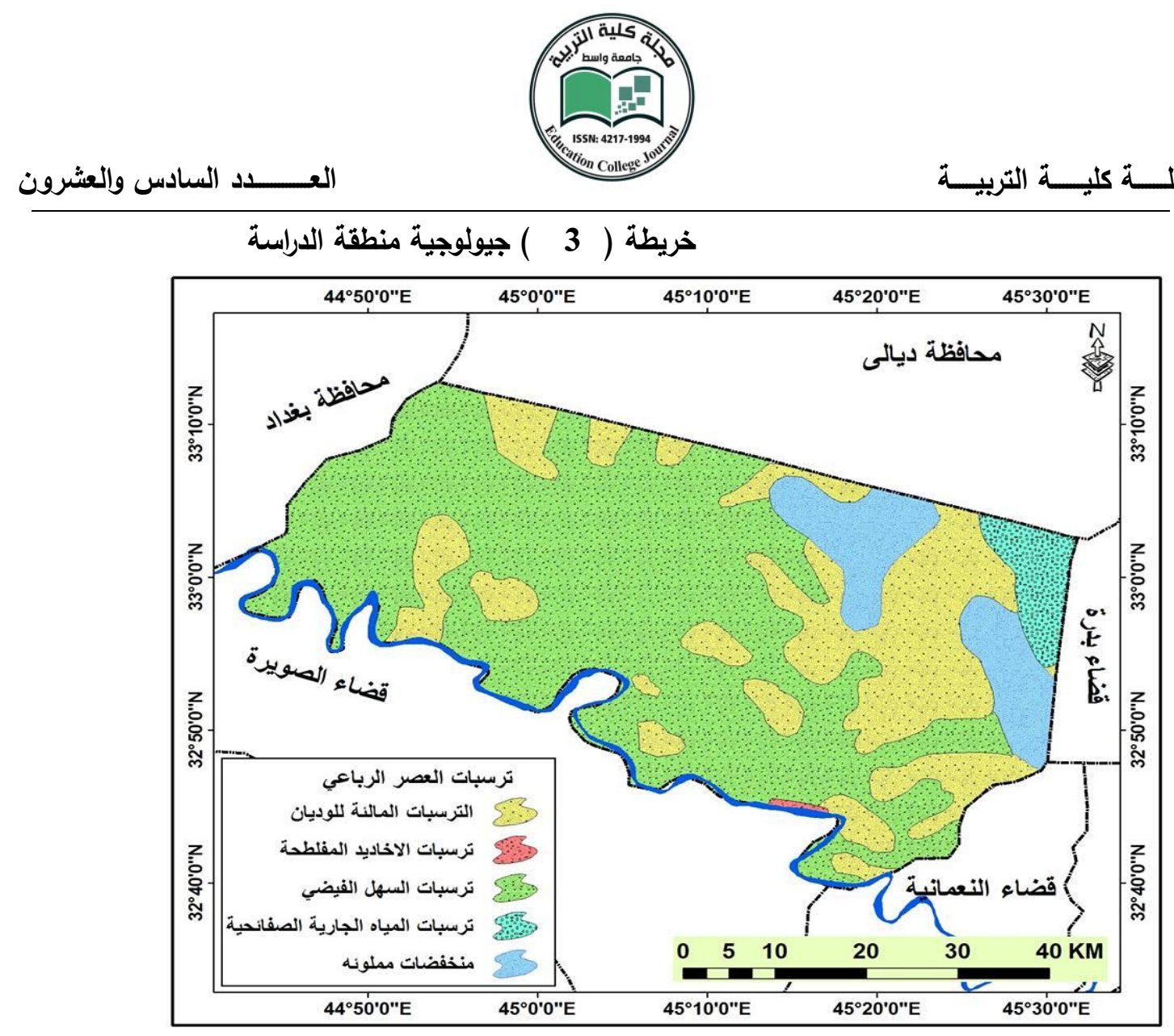

المصدر:من عمل الباحث بالاعتماد على الثركة العامة للمسح الجيولوجي والتعدين، التقرير الجيولوجي عن

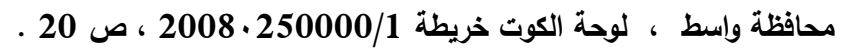

السطح:

يشكل قضاء العزيزية جزءاً من السهل الرسوبي الذي يمتاز بإستواء السطح والانخفاض التدريجي كلَما تقدمنا إلى الجنوب ( النقاش ، 1989) يتميز موقع القضاء بوجود مناطق متفاوتة في الارتفاع ضمن أراضيه ادى إلى ارتفاع منسوب المياه الجوفية في المناطق المنخفضة .كما يمتاز سطح القضاء بوجود مناطق مرتفعة تمتلت بالسداد الطبيعية على جانبي نهر دجلة وبعض التلال التي تختلف مستوى ارتفاعها منل تلال ضباعي وتلول الدير شمال ناحية العزيزية وتلول خيط الجباب في ناحية الشحيمية. ( رسن، واخرون ،2015،ص 41 ) وتتنتر بعض الأشكال التضاريسية من صنع الإنسان تمثلت بالمشاريع الإروائية 
القديمة حيث تتميز منطقة الدراسة بكثرة هذه المشاريع لانتشار الاراضي الزراعية في مختلف اجزاء القضاء. مما تتعكس على طبيعة السطح من مناطق منخفضة مملوءة بالمياه ومناطق مرتفعة تعود لبقايا عمليات الحفر لتلك المشاريع وإحدى صفات التربة هي القدرة على تغلغل الماء. عندما ينفذ الماء للتربة قسم منه يتغلغل ويصل لمجمعات تحت الأرض ، وقسم منه ييقى منماسكاً بين حبيبات التربة. ولصفة التربة هذه تأثثر على مجمعات الماء من جهة، و على النباتات التي نتمو فيها من جهة أُخرى.

\section{- :المناخ}

تُعد عناصر المناخ ولاسيما عنصري الأمطار ودرجة الحرارة ذا أثز واضح في تغذية المياه الجوفية وكمية المياه المتبخرة فضلاً عن تأثيرها على اختلاف نراكيز العناصر الكيميائية أما بقية العناصر المناخية فإن أثرها متفاوت بحسب الظروف الطبيعية للسطح ونوع الترب وعمق المياه الجوفية ـ تقع منطقة الدراسة

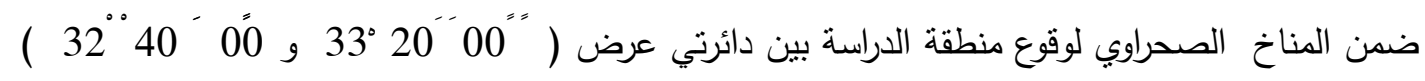
مما ينعكس على قِلة الأمطار واعتدال درجات الحرارة شتاءً وارتفاعها صيفاً وفي ظل البيانات المناخية لمحطة العزيزية تقع منطقة الدراسة ضمن المناخ الجاف.

\section{درجة الحراة:}

تؤثر درجات الحرارة بشكل كبير وواضح على المياه الجوفية من خلال رفع قيمة التبخر الذي يقلل من كمية المياه المغذية خاصةً وان المنطقة تشهد إرتفاع درجات الحرارة لمعظم فصول السنة إذ سجلت محطة العزيزية إرتفاع معدلات درجات الحرارة لأكثر من ثمانية أثهر سجلت اكثر من( 18مْ) وتصل أعلى دئ معدلاتها في الأشهر (حزيران وتموز واب) بمعدلات ( 38.0 - 36.7 - 36.5 ) ) على التوالي ،جدول (1) وشكل (1) حيث تعمل درجات الحرارة على إنخفاض كميات المياه المغذية الضائعة نتيجة إرتفاع قيمة 
العــــــــد السادس والعشرون

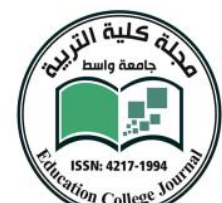

جدول ( 1 ) ): معدل درجات الحرارة (مْ) لمحطة العزيزية لسنة (2015)

المصدر :. وزارة النقل والمواصلات، الهيأة العامة للانواء الجوية والرصد الزلزالي العراقية،قسم المناخ(بيانات غير منشورة)

\begin{tabular}{|c|c|c|c|c|c|c|c|c|c|c|c|c|c|}
\hline المبنوي & كانون & تثثرين & تالاول & ايلول & اب & تموز & نزيرا & مايس & نيسان & اذار & شباط & كانون & المحطة \\
\hline 24.6 & 12.2 & 18.7 & 28.1 & $\begin{array}{l}32 . \\
3\end{array}$ & 38 & $\begin{array}{l}36 . \\
7\end{array}$ & 36.5 & $\begin{array}{l}30 . \\
7\end{array}$ & 20.5 & $\begin{array}{l}13 . \\
8\end{array}$ & 19.5 & 8.7 & العزيزية \\
\hline
\end{tabular}

شكل ( 1 ) منحنى بياني لمعل درجات الحرارة لمحطة العزيزية لسنة (2015 )

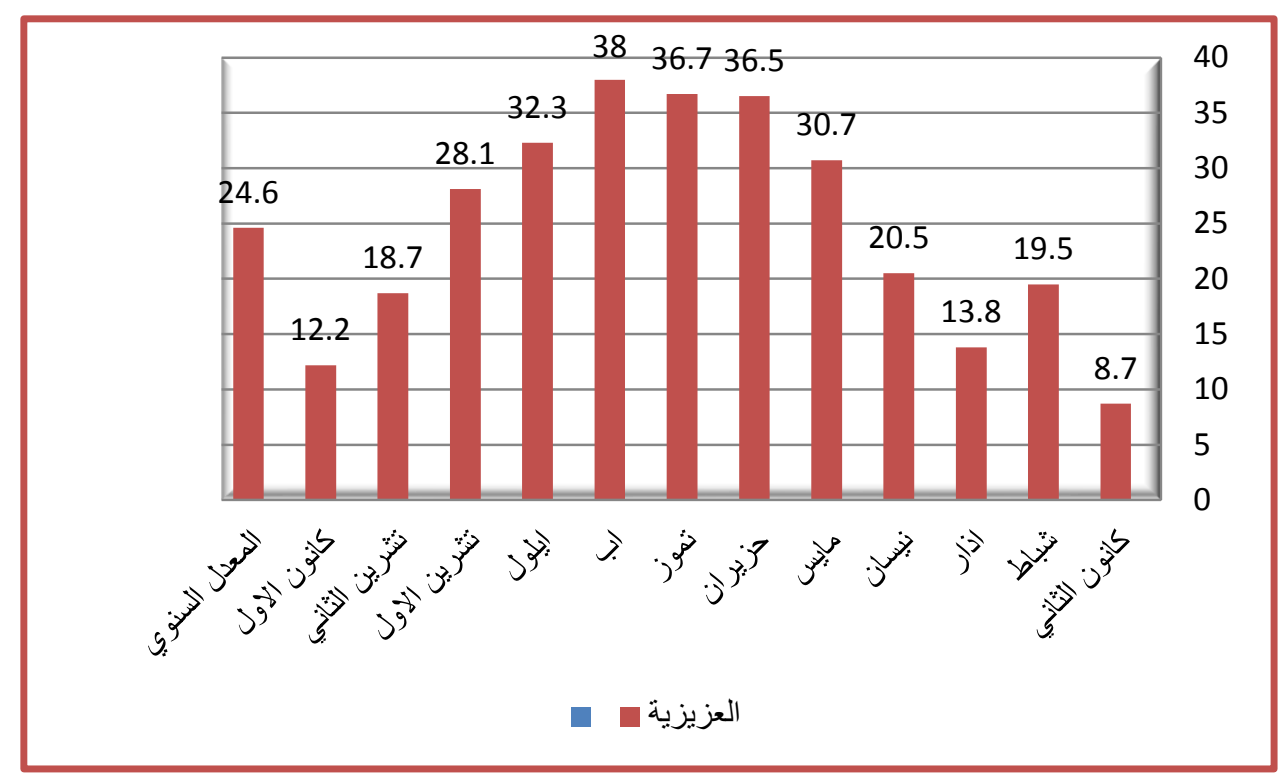

المصدر: من عمل الباحث بالاعتماد على جدول ( 1 )

Mo 
تُعد الأمطار مصدر التغذية الرئيسي للمياه الجوفية إذ تتذبذب كمياتها من فصل لآخر مما ينعكس على تغير مناسيبها، وتعمل الأمطار على إذابة الأملاح وبعض العناصر الكيميائية القابلة للذوبان مما يعمل على تغير الخواص الطبيعية للمياه ويؤثز على مدى صلاحيتها . إذ سجلت منطقة الدراسة أعلى معدل أمطار في شهر كانون الثاني مقارنةً مع بقية الأشهر ، اذا بلغت ( 24.9 ).

أما التبخر يسبب فقدان كميات كبيرة من المياه المغذية عن طريق تبخر المياه السطحية مما ينعكس على إنخفاض منسوب الماء الجوفي ، هذا وقد سجلت المنطقة إرتفاع في قيمة التبخر وخاصة لثهر تموز إذ بلغت قيمته (629.4) •جدول ( 2 ) ) وشكل (2)

جدول ( 2 ): المجموع الثهري والسنوي لكمية الأمطار والتبخر (ملم) لمحطة العزيزية (2015 )

\begin{tabular}{|c|c|c|c|c|c|c|c|c|c|c|c|c|c|}
\hline المجنوع & كانون & تشرين & تشرين & ايلول & آب & تموز & حزيران & مايس & نيسان & آذار & شباط & كانون & العزيزية \\
\hline 126 & 16.9 & 17.6 & 9.2 & 0.2 & 0 & 0 & 0 & 7.5 & 18.4 & 15.6 & 15.7 & 24.9 & امطار \\
\hline 3702.5 & 97.1 & 137.2 & 269.9 & 421.2 & 546 & 629.4 & 568.3 & 336.3 & 274 & 219.9 & 121.7 & 81.5 & تبخر \\
\hline
\end{tabular}

المصدر:. وزارة النقل والمواصلات، الهيأة العامة للانواء الجوية والرصد الززلزالي العراقية،قسم المناخ(بيانات غير منشورة) 

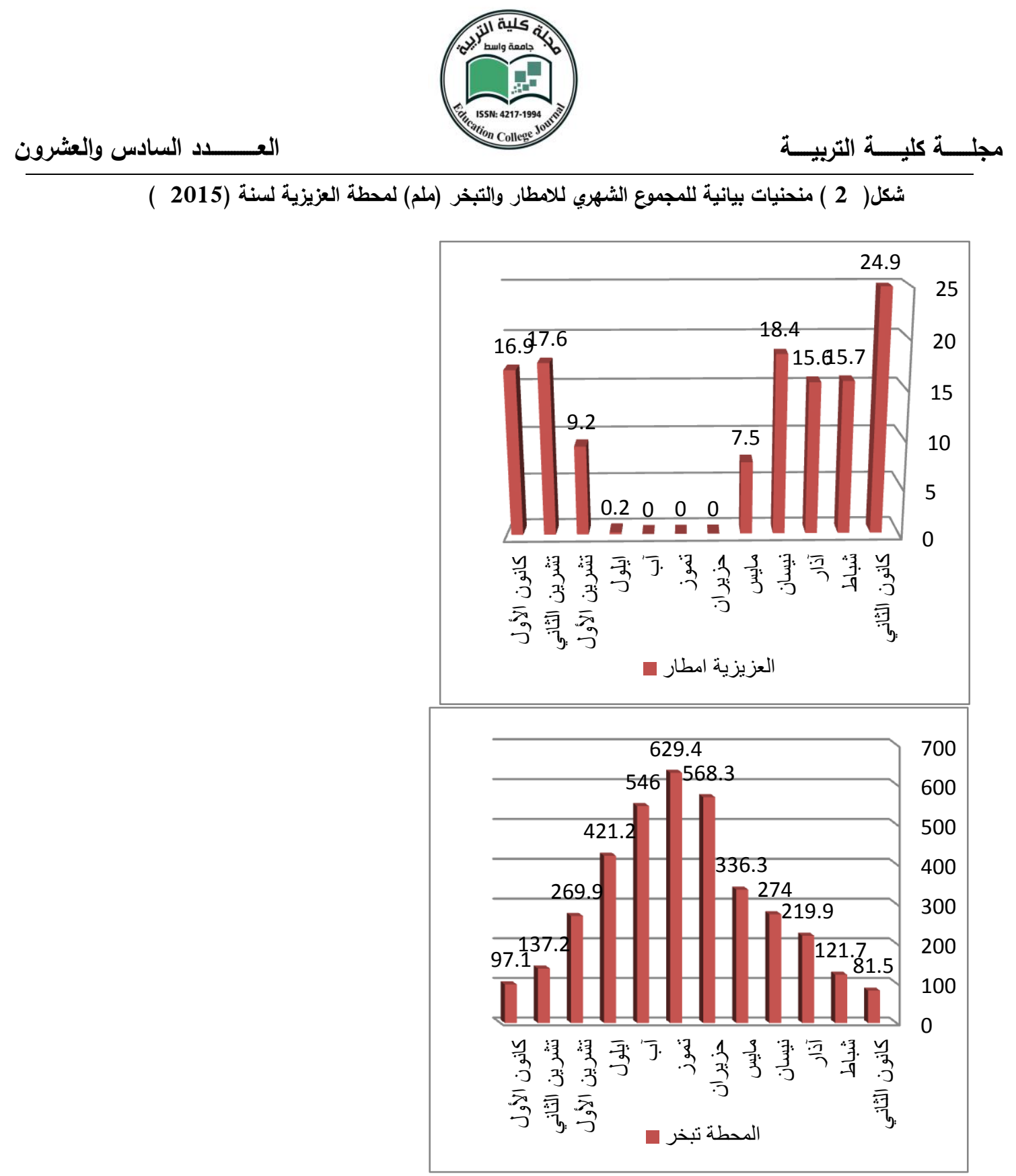

المصدر: من عمل الباحث بالاعتماد على جدول ( 2 ) 
للتربة دورٌ كبير في تحديد كمية المياه المتغلغلة، فكلما كانت التربة ذات نفاذية عالية تسمح للماء لتغلغل أسرع، حيث يملأ الماء بصورة كاملة الفراغات الموجودة بين الصخور وذرات التربة. ويمكن للناس حفر الآبار داخل هذه المنطقة وضخ الماء إلى الخارج. عندها تصل أكثر كمية تغذية للمياه الجوفية وتُخزن هنالك.إذ أن منطقة الدراسة تحوي على تربة رسوبية تكونت نتيجة نقل مياه النهر للمواد الغربنية والرملية والحصوية إذ تمناز بأنها ذات ذرات خشنة وذلك لأنها من الترسبات التي كونتها مياه النهر كما ترتفع نسبة

$$
\text { الطين فيها. ( الجبوري ، 2008،ص لص } 83 \text { ). }
$$

تقع منطقة الدراسة ضمن نرب كتوف الأنهار وتربة الأحواض وجميع هذه الترب تُعد ملحية بفعل الخاصية الشعرية للمياه ، إذ أن تربة منطقة الدراسة عملت على زيادة تغذية المياه الجوفية من خلال طبيعة التربة التي سمحت بتغلغل كميات من مباه الامطار في المنطقة (المسعودي، 2014 ، ص122 ) .

\section{التبات الطبيعي :}

للنبات الطبيعي أتزر كبير في تغلغل مياه الأمطار الى داخل التربة حيث تسمح الفراغات بين جذور النبات بنفاذ قطرات المطر إلى داخل الأرض لتكون فيما بعد خزين إضافي للمياه الجوفية، كما يعمل النبات على تقليل شدة التبخر من السطح وبالتالي ينعكس على الكميات المغذية للمياه الجوفية ،إذ تتميز منطقة الدراسة بتباين نوعية وكثافة النبات الطبيعي لتتوع مصادر المياه السطحية والجوفية في المنطقة إذ تتنتر العديد من الأنواع منها نباتات ضفاف الأنهار ونباتات السهل الفيضي وهي نباتات عصارية او شوكية منتشرة في الأراضي التي تعرضت لظاهرة التغدق ( الخشاب وحديد ، بدون سنة طبع، ص23 من ).

\section{الخصائص البشربية :}

يُعد السكان مؤثراً رئيسياً في تغير خصائص المياه الجوفية وزيادة المواد الملوثة من خلال الأنشطة المختلفة بشكل غير مباثر عن طريق الملوثات التي تلقى في النهر وتصل الى المياه الجوفية عن طريق التغذية، وبشكل مباشر ما ترشحه الترب من ملوثات السكان المختلفة زراعية ورعي او صناعية او مياه 


\section{العـــــــد السادس والعثرون \\ صرف صحي. وبلغ سكان قضاء العزيزية (120000) نسمة عام (2014) (وزارة التخطيط،2014)هذا \\ • ويمارس سكان القضاء الزراعة كنشاط رئيسي \\ -}

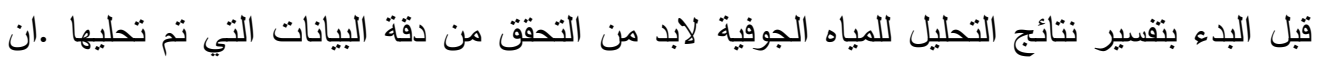

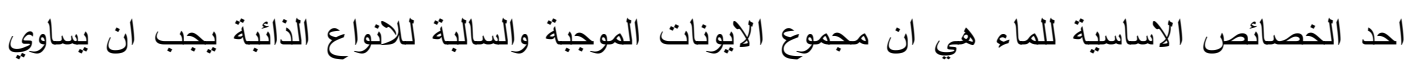

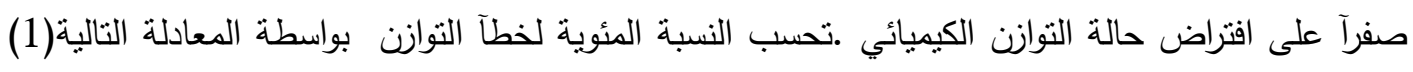

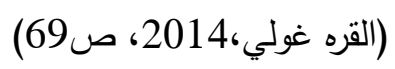

Balance error $(\%)=\frac{\sum \text { cations }-\sum \text { Anion }}{\sum \text { cations }+\sum \text { Anion }} \times 100$ إذ يعبر عن التراكيز ( / / (epm).

إذا كانت النسبة المئوية لخظأ النوازن أقل من (5\%) فهذا يعني أن نتائج التحليل جيدة ، أما إذا كانت النتائج مابين ( 5 - 10\%) فهي مهمة وضمن المدى المقبول وتدل على أن التنادل في الآيونات والتناعلات

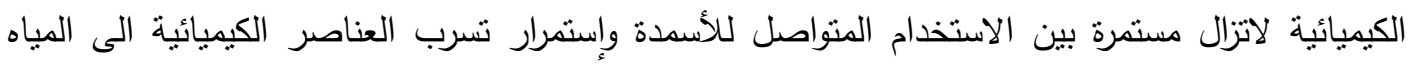
الجوفية، وإذا كان الإختلاف أكبر من ( 10\%) فأن ذلك يعني ان هنالك مشكلة في التحليل وبذلك تهمل . (faris, 2009 )

ومن خلال ذلك نلاحظ في جدول (3 ) أن القيمة المحسوبة لخطأ النوازن لعينات المياه الجوفية غالبيتها

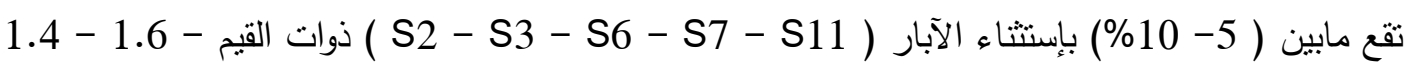

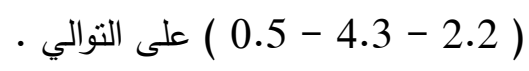


العـــــــد السادس والعشرون

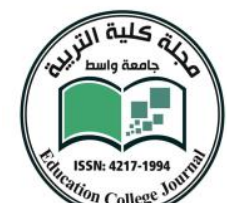

جدول ( 3 ) القياسات الفيزيائية والتحاليل الكيميائية للمياه الجوفية في منطقة الدراسة 2016

\begin{tabular}{|c|c|c|c|c|c|c|c|c|c|c|c|c|c|}
\hline رقم العينة & $\mathrm{PH}$ & TDS & EC & $\begin{array}{l}\mathrm{TH} \\
\mathrm{ppm}\end{array}$ & $\mathrm{Ca}$ & $\mathbf{M g}$ & $\mathrm{Na}$ & K & SO4 & $\begin{array}{c}\mathrm{HCO} \\
\mathbf{3}\end{array}$ & CL & $\begin{array}{c}\text { UNI } \\
\text { T }\end{array}$ & $\begin{array}{c}\text { نسبة خطأ } \\
\text { نتوازن } \\
\text { (epm) }\end{array}$ \\
\hline \multirow[b]{2}{*}{ s1 } & \multirow[b]{2}{*}{9.4} & \multirow[b]{2}{*}{3250} & \multirow{2}{*}{$\begin{array}{c}395 \\
0\end{array}$} & \multirow{2}{*}{$\begin{array}{c}210 \\
2\end{array}$} & 583 & 686 & 792 & 6.3 & 2360 & 348 & 1670 & Ppm & \multirow[t]{2}{*}{8.1} \\
\hline & & & & & $\begin{array}{c}29.0 \\
9\end{array}$ & $\begin{array}{c}56.4 \\
3\end{array}$ & $\begin{array}{c}34.4 \\
5\end{array}$ & $\begin{array}{c}0.1 \\
6\end{array}$ & $\begin{array}{c}49.1 \\
3\end{array}$ & 5.70 & $\begin{array}{c}47.1 \\
1\end{array}$ & Epm & \\
\hline \multirow[b]{2}{*}{ S2 } & \multirow[b]{2}{*}{9} & \multirow[b]{2}{*}{2281} & \multirow{2}{*}{$\begin{array}{c}337 \\
0\end{array}$} & \multirow{2}{*}{$\begin{array}{c}193 \\
0\end{array}$} & 698 & 561 & 685 & 6.9 & 2593 & 278 & 1749 & Ppm & \multirow[t]{2}{*}{1.4} \\
\hline & & & & & $\begin{array}{c}34.8 \\
3\end{array}$ & $\begin{array}{c}46.1 \\
4\end{array}$ & $\begin{array}{c}29.7 \\
9\end{array}$ & $\begin{array}{c}0.1 \\
7\end{array}$ & $\begin{array}{c}53.9 \\
8\end{array}$ & 4.55 & $\begin{array}{c}49.3 \\
3\end{array}$ & Epm & \\
\hline \multirow{2}{*}{ s3 } & \multirow{2}{*}{8.7} & \multirow{2}{*}{809} & \multirow{2}{*}{$\begin{array}{c}110 \\
6\end{array}$} & \multirow{2}{*}{830} & 137 & 88 & 160 & 4 & 470 & 188 & 269 & Ppm & \multirow[t]{2}{*}{1.6} \\
\hline & & & & & 6.83 & 7.23 & 6.96 & 0.1 & 9.78 & 3.08 & 7.58 & Epm & \\
\hline \multirow[b]{2}{*}{ S4 } & \multirow[b]{2}{*}{8.4} & \multirow[b]{2}{*}{689} & \multirow[b]{2}{*}{820} & \multirow[b]{2}{*}{571} & 609 & 570 & 586 & 2.9 & 2420 & 201 & 1389 & Ppm & \multirow[t]{2}{*}{5.1} \\
\hline & & & & & $\begin{array}{c}30.3 \\
8\end{array}$ & $\begin{array}{c}46.8 \\
8\end{array}$ & $\begin{array}{c}25.4 \\
9\end{array}$ & $\begin{array}{c}0.0 \\
9\end{array}$ & $\begin{array}{c}50.3 \\
8\end{array}$ & 3.29 & $\begin{array}{c}39.1 \\
8\end{array}$ & Epm & \\
\hline \multirow[b]{2}{*}{ S5 } & \multirow[b]{2}{*}{8.7} & \multirow[b]{2}{*}{1805} & \multirow{2}{*}{$\begin{array}{c}220 \\
5\end{array}$} & \multirow{2}{*}{$\begin{array}{c}145 \\
7\end{array}$} & 141 & 195 & 301 & 4.6 & 560 & 299 & 492 & Ppm & \multirow[t]{2}{*}{8.8} \\
\hline & & & & & 7.03 & $\begin{array}{c}16.0 \\
4\end{array}$ & $\begin{array}{c}13.0 \\
9\end{array}$ & $\begin{array}{c}0.1 \\
4\end{array}$ & $\begin{array}{c}11.6 \\
5\end{array}$ & 4.90 & $\begin{array}{c}13.8 \\
7\end{array}$ & Epm & \\
\hline & & & & & 321 & 578 & 525 & 4 & 2299 & 251 & 1189 & Ppm & 0.5 \\
\hline s6 & 8.5 & 2090 & 0 & 1 & $\begin{array}{c}16.0 \\
1\end{array}$ & $\begin{array}{c}47.5 \\
4\end{array}$ & $\begin{array}{c}22.8 \\
3\end{array}$ & 0.1 & $\begin{array}{c}47.8 \\
6\end{array}$ & 4.11 & $\begin{array}{c}33.5 \\
4\end{array}$ & Epm & \\
\hline & & & & & 418 & 569 & 523 & 3.2 & 2211 & 248 & 1180 & Ppm & 4.3 \\
\hline s7 & 8.6 & 1843 & 9 & 8 & $\begin{array}{c}20.8 \\
5 \\
\end{array}$ & $\begin{array}{c}46.8 \\
0 \\
\end{array}$ & $\begin{array}{c}22.7 \\
5 \\
\end{array}$ & $\begin{array}{c}0.0 \\
8 \\
\end{array}$ & $\begin{array}{c}46.0 \\
3 \\
\end{array}$ & 4.03 & $\begin{array}{c}33.2 \\
8 \\
\end{array}$ & Epm & \\
\hline & & & & & 320 & 236 & 440 & 3 & 404 & 233 & 1177 & Ppm & 9.1 \\
\hline s8 & 8.7 & 421 & 690 & 350 & $\begin{array}{c}15.9 \\
6\end{array}$ & $\begin{array}{c}19.4 \\
1 \\
\end{array}$ & $\begin{array}{c}19.1 \\
4\end{array}$ & $\begin{array}{c}0.0 \\
7\end{array}$ & 8.41 & 3.81 & 33.2 & Epm & \\
\hline & & & & & 376 & 341 & 343 & 3.2 & 670 & 245 & 1190 & Ppm & 9.5 \\
\hline s9 & 8.6 & 405 & 558 & 377 & $\begin{array}{c}18.7 \\
6\end{array}$ & $\begin{array}{c}28.0 \\
5\end{array}$ & $\begin{array}{c}14.9 \\
2\end{array}$ & $\begin{array}{c}0.0 \\
8\end{array}$ & $\begin{array}{c}13.4 \\
9\end{array}$ & 4.01 & $\begin{array}{c}33.5 \\
6\end{array}$ & Epm & \\
\hline & & & & & 609 & 690 & 710 & 7.1 & 2240 & 293 & 1682 & Ppm & 8.9 \\
\hline S10 & 8.4 & 1961 & 0 & 1 & $\begin{array}{c}30.3 \\
8\end{array}$ & $\begin{array}{c}56.7 \\
5\end{array}$ & $\begin{array}{c}30.8 \\
8\end{array}$ & 0.2 & $\begin{array}{c}46.6 \\
3\end{array}$ & 4.80 & $\begin{array}{c}47.4 \\
4\end{array}$ & Epm & \\
\hline & & & & & 144 & 99 & 161 & 2.5 & 501 & 189 & 279 & Ppm & 2.2 \\
\hline s11 & 8.5 & 627 & 790 & 446 & 7.18 & 8.14 & 7 & $\begin{array}{c}0.0 \\
6\end{array}$ & $\begin{array}{c}10.4 \\
3\end{array}$ & 3.09 & 7.87 & Epm & \\
\hline S12 & 92 & 2815 & 301 & 122 & 517 & 641 & 619 & 5 & 2250 & 243 & 1567 & Ppm & 5.2 \\
\hline & & & 1 & 3 & 25.7 & 52.7 & 26.9 & 0.1 & 46.8 & 3.98 & 44.2 & epm & \\
\hline
\end{tabular}

Tr. 


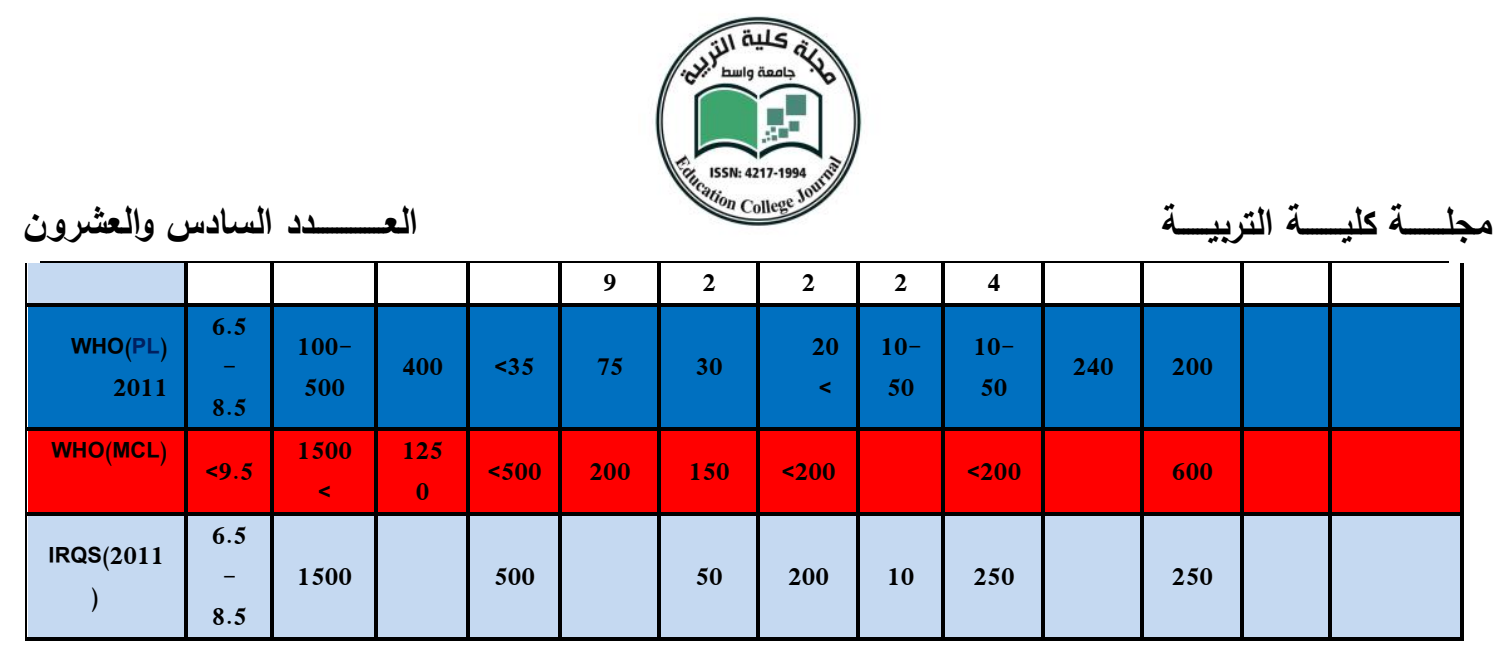

المصدر: وزارة العلوم والتكنولوجيا، دائرة البيئة وإلمياه ، مختبر اعادة تدوير المياه .

ملاحظة: الارقام الحمراء(MCL) تثثير الى اعلى مستوى للتلوث، اما الارقام الزرقاء) (PL) تثير الى الحد المسموح للتلوث، اما تثثير الى المواصفات العراقية.المقاسة (IRQS)

\section{2-تصنيف المياه بحسب تراكيز الايونات الرئيسة :}

يَعتمد تصنيف نوعية المياه الجوفية على وفق معادلة كورولوف (kurolov -formula)على نسبة تراكيز الآيونات الرئيسة فيها تُعد قيمة الآيونات الموجبة والسالبة التي تزبد تراكيزها عن ( 15\%)من وحدة (epm \%) الصيغة الهيدروكيمائية فأنها تمثل النسبة الوزنية المكافئة لكل الآيونات الرئيسة الموجبة والسالبة مرتبطة بإنتظام بحسب نزكيز كل منها في المياه كذلك مقدار الملوحة (TDS mg/L) و (الاس الهيدروجيني PH

$$
\left[\left[T \cdot D \cdot S(m g / L)=\frac{\mathrm{SO}_{4}(e p m \%) \cdot \mathrm{Cl}(\mathrm{epm} \%) \cdot \mathrm{HCO}_{3}(\mathrm{epm} \%)}{\mathrm{Ca}(\mathrm{epm} \%) \cdot \mathrm{Na}(\mathrm{epm} \%) \cdot \mathrm{Mg}(\mathrm{epm} \%) \cdot \mathrm{K}(\mathrm{epm} \%)}(\mathrm{PH})\right]\right]
$$

وقد طبقت هذة المعادلة على جميع عينات المياه وباستخدام برنامج ( Aquachem v-4). وقد أظهرت النتائج كما في جدول ( 4) هي من نوع (Sulfat water type ) مع تغير الآيونات الموجبة والسالبة حيث نكون بالصيغة التالية ( Mg - Na - Ca - CL - Sulfute). مع تغاير ضعيف في موقع وترتيب هذة الايونات . 
العـــــــد السادس والعشرون

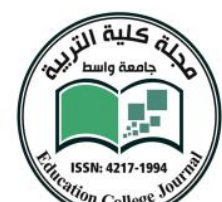

أما سبب إغناء هذة المياه بالكبريت فيرجع إلى وجود الكبريتات بشكل رئيسي في المنطقة على شكل معدن الجبس.

وقد صُنفت هذه المياه الى خمسة أصناف كلاً حسب تشابهها من حيث المكونات الكيميائية ونت توزيعها

مكانياً كما في خربطة (4)

جدول ( 4 ) الصيغة الهيدروكيميائية ونوعية المياه لنماذج مياه الابار

\begin{tabular}{|c|c|c|}
\hline رقم العينة & الصيغة الهيلروكيميائية & نوعية المياه \\
\hline s1 & $\begin{array}{l}3250 \\
\frac{\mathrm{SO}_{4}(48.19) \cdot \mathrm{Cl}(46.21 \quad) \cdot \mathrm{HCO}{ }_{3}(5.59)}{\mathrm{Ca}(24.21 \quad) \cdot \mathrm{Na}(28.67 \quad) \cdot \mathrm{Mg}(46.97 \quad) \cdot \mathrm{K}(0.13)} 9.4\end{array}$ & $\mathrm{Mg}-\mathrm{Na}-\mathrm{Ca}-\mathrm{Cl}-\mathrm{Sulfate}$ \\
\hline s2 & 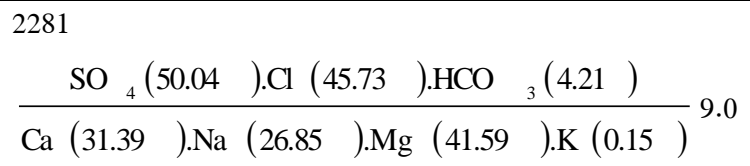 & $\mathrm{Mg}-\mathrm{Ca}-\mathrm{Na}-\mathrm{Cl}-$ Sulfate \\
\hline s3 & $\begin{array}{l}809 \frac{\mathrm{SO}_{4}(47.84) \cdot \mathrm{Cl}(37.08 \quad) \cdot \mathrm{HCO}}{3}(15.06 \quad) \\
\mathrm{Ca}(32.33 \quad) \cdot \mathrm{Na}(32.95 \quad) \cdot \mathrm{Mg}(34.23 \quad) \cdot \mathrm{K}(0.47)\end{array}$ & $\mathrm{Mg}-\mathrm{Na}-\mathrm{Ca}-\mathrm{Cl}-\mathrm{Sulfate}$ \\
\hline S4 & 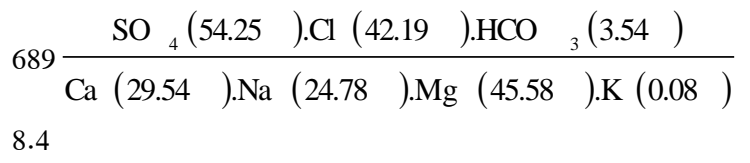 & $\mathrm{Mg}-\mathrm{Ca}-\mathrm{Na}-\mathrm{Cl}-$ Sulfate \\
\hline S5 & 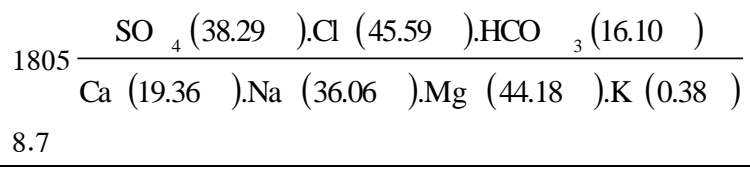 & $\mathrm{Mg}-\mathrm{Na}-\mathrm{Ca}-\mathrm{HCO} 3-\mathrm{SO} 4-\mathrm{Cl}$ \\
\hline s6 & $\begin{array}{l}\left.2090 \frac{\mathrm{SO}_{4}(55.97}{\mathrm{Ca}(18.51}\right) \cdot \mathrm{Cl}(39.22) \cdot \mathrm{Na}(26.39) \cdot \mathrm{Hg}(54.97 \quad) \cdot \mathrm{K}(0.11) \\
8.5\end{array}$ & $\mathrm{Mg}-\mathrm{Na}-\mathrm{Ca}-\mathrm{Cl}-$ Sulfate \\
\hline
\end{tabular}


العــــــدد السادس والعشرون

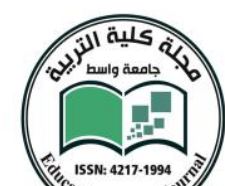

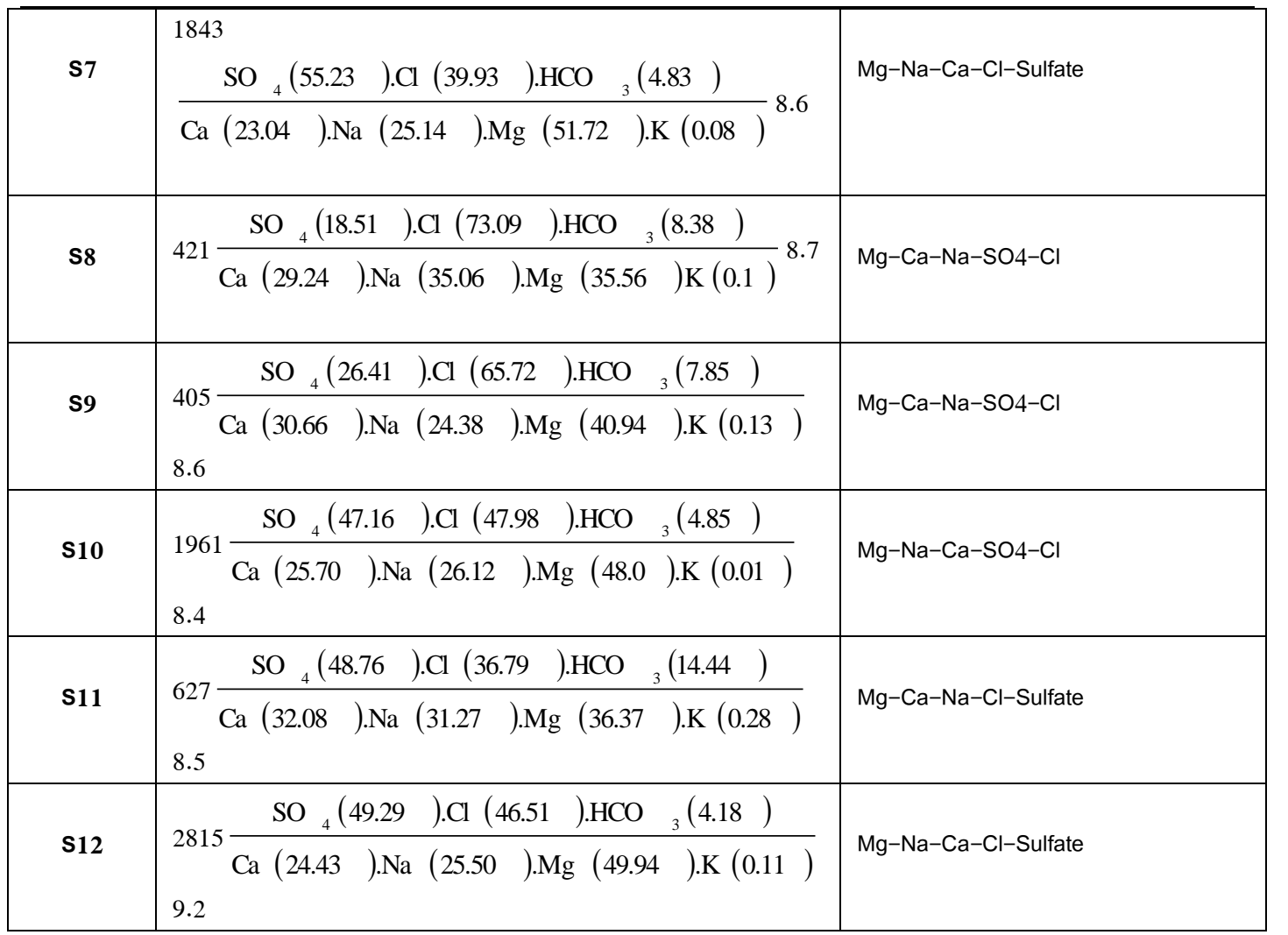

المصدر: من عمل الباحث بالاعتماد على معادلة (2 ) 
العــــــــد السادس والعشرون

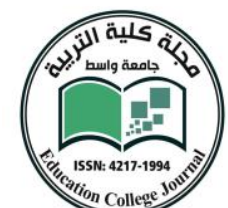

خريطة ( 4 ) صنوف المياه بحسب تراكيز العناصر الكيمياوية 1 ا ب r

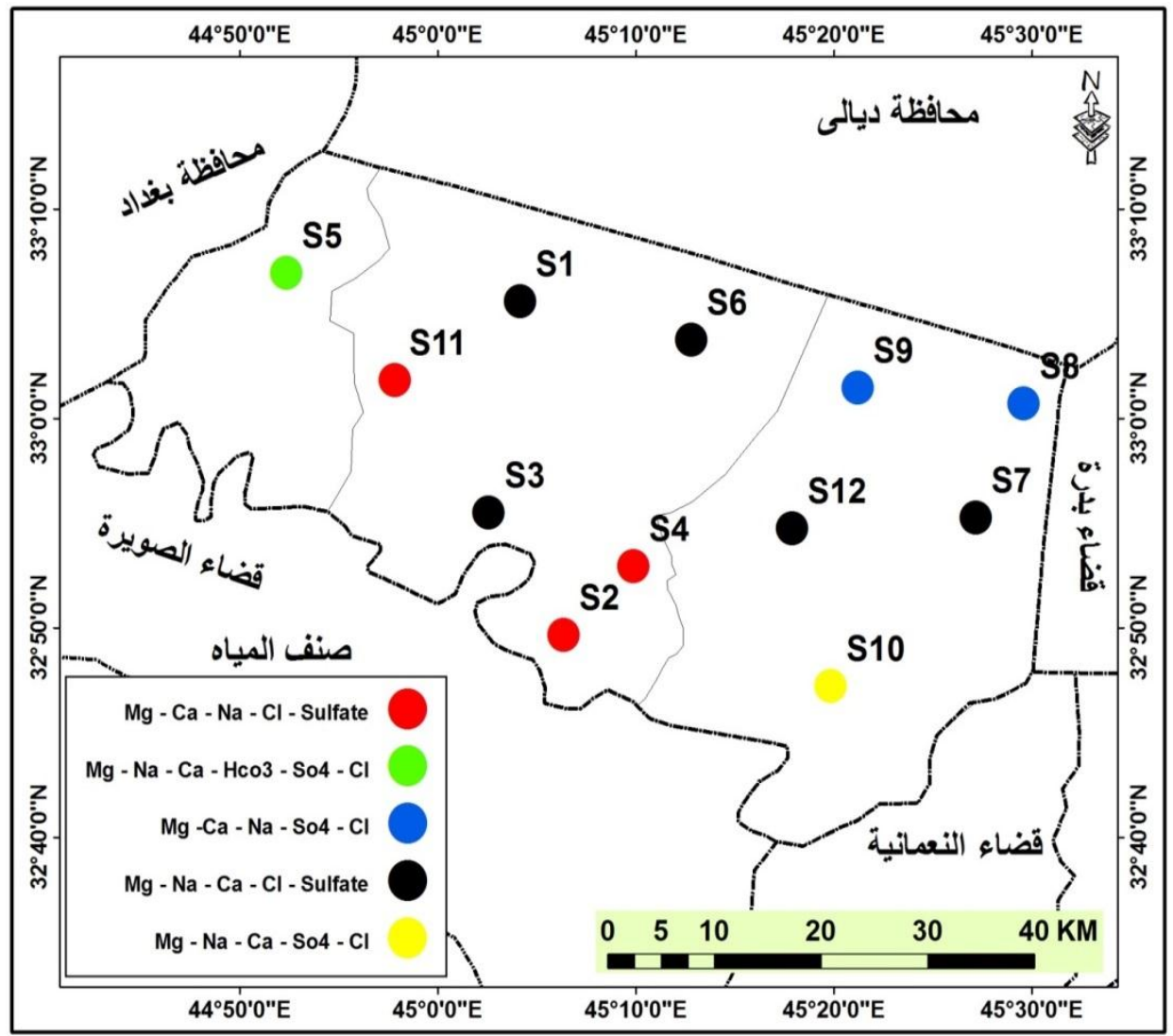

المصدر : من عمل الباحث بالاعتماد على جلول ( 4 )

\section{3-البة التحكم في كيميائية المباه الجوفية}

لقد ناقش الباحث الآليات المتتوعة التي تتظم التركيبة الكيميائية للمياه وعلاقتها بالصخور الحاوية لها ومن هذه الآليات وأهمها هو مخطط كَبس (Gibbs diagram).وهو مخطط اقترحه كَبس (Gibbs). قائماً على أساس النسب بصفتها احدى وظائف وقياس تحليل المواد الصلبة الذائبة (TDS)ويستخدم على نطاق واسع لدراسته العلاقة بين تكوين المياه الجوفية والخصائص الصخارية ، ويثنير إلى أن هنالك ثلاثثة مصادر 
للمكونات الكيميائية الذائبة هي سيادة هطول الأمطار وسيادة التبخر وسيادة تفاعل الصخور ( Xing, et. al

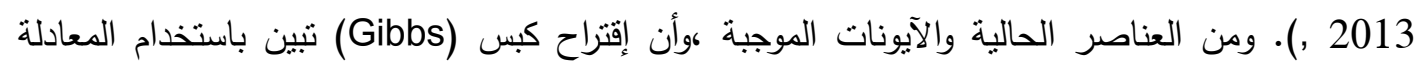
(3). الاتية

$$
1-\text { Gibb 's Ratio }-1=\frac{C L}{\left(\mathrm{CL}+\mathrm{HCO}_{3}\right)} \text { for anions }
$$$$
2-G i b b \text { 's Ratio }-11=\frac{N a+K}{N a+K+C a} \text { for cations }
$$

إذ يعبر عن الآيونات كافة ) (epmLL)

وطبقاً لمخطط كبس (Gibbs) يكون التركيز الكيميائي للمياه الجوفية في منطقة الدراسة ضمن سيادة التبخر والصخور شكل (3) وجدول ( 5 ) ). نلاحظ أن سيادة الصخور قليلة مقارنة بالتبخر ولآيونات

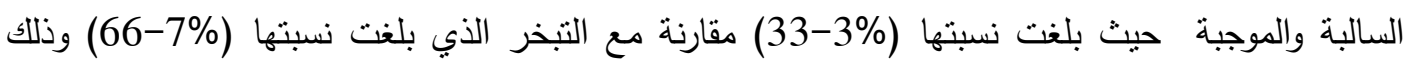

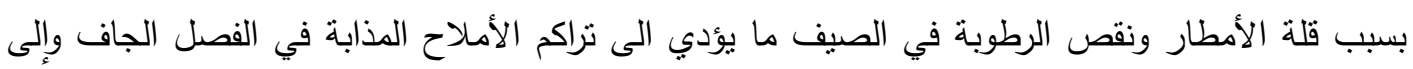
تسرب في النهاية إلى التربة وبعدها للمياه. 

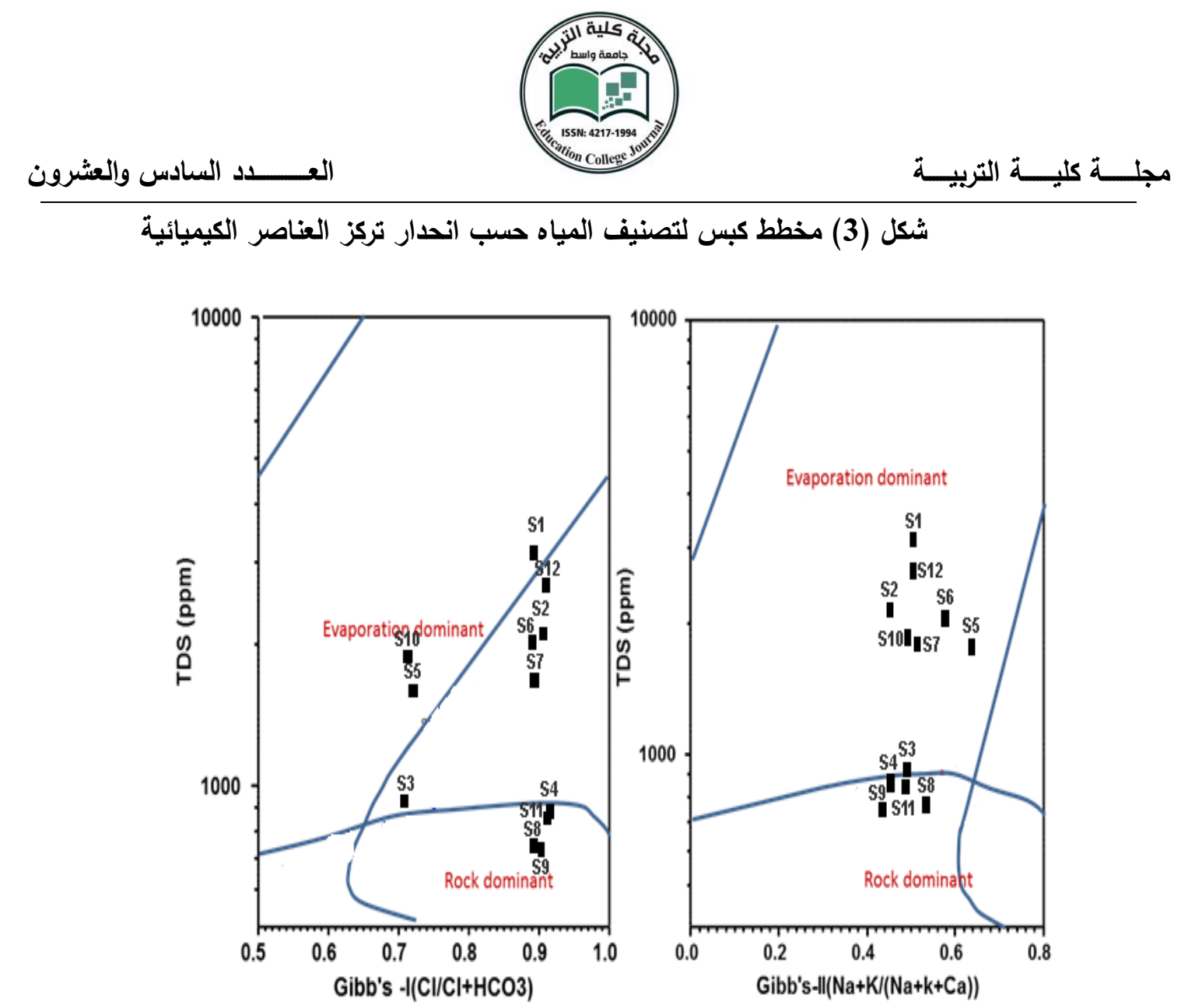

(Aquachem v.4) المصدر:من عمل الباحث:بالاعتماد على : برنامج

جدول ( 5 ) عينات المياه وفق تطبيق كَبس( Gibbs )

\begin{tabular}{|c|c|c|}
\hline \multicolumn{2}{|c|}{ النسبة (\%) المئوية } & \multirow{2}{*}{$\begin{array}{l}\text { Ratio } \\
\text { Raبة }\end{array}$} \\
\hline $\begin{array}{c}\text { سيادة الصخور } \\
\text { Rock Dominance }\end{array}$ & $\begin{array}{c}\text { سيادة التبخر } \\
\text { Evaporation }\end{array}$ & \\
\hline 33.3 & 66.7 & ratio Anion نسبة الآيونات السالبة \\
\hline 33.3 & 66.7 & نation ratio نسبة الآيونات الموجبة \\
\hline
\end{tabular}

المصدر : من عمل الباحث بالاعتماد على شكل (3) 
العــــــد السادس والعشرون

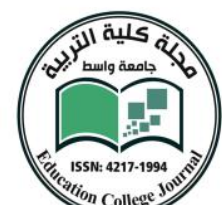

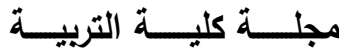

4- تقبم نوعية مباه منقطقة الارلسة للأغراض المختلفة :

لبيان الاستفادة من المياه الجوفية في منطقة الدراسة ومعرفة مجالات إستخدامها وضمان سلامة المستهلكين لها ـ ثم تقيم نتائج تحاليل النماذج المائية مع المواصفات الدولية والعراقية للأغراض المختلفة .

\section{4-1- تقبم صلاحية المباه الحوفية للاغراض شرب الانسان :}

لغرض تقيم مياه المنطقة ثم مقارنة محتوياتها بالمواصفات القياسية العراقية(IRQ11996- 2006) والمواصفات القياسية العالمية للتلوث (2011-211 ) وهي على مستوى الأول فوق أعلى مستوى للنلوث (MCL) والمستوى الثاني (PL) الحد المسموح به ومقارنتها مع المتغيرات الكيميائية في جدول (3 ) يظهرعند مقارنة نتائج التحاليل الكيميائي عن المواصفة السابقة الذكر إن مياه منطقة الدراسة لا تصلح لثرب الانسان لزيادة أغلب تراكيز العناصر للحدود المسموح بها.

\section{4-4}

إنَ للمياه الجوفية أهمية كبيرة وضرورية لغرض الري • وتقيم مدى صلاحيتها للري على المتغيرات الهيدروكيميائية المنمثلة بالأملاح المذابة ونسبة الصوديوم وعلى نسبة إمتزاز الصوديوم ( SAR) والنسبة المؤية للصوديوم (Na\%) الموجودة في جدول (6) وهي من المعايير الأكثر أهمية في جودة ( Deshpund (and Aher,2012) وإستخدام أيضآ مخطط ريتشارد (Richard,1954) (and )

(SAR ) 1-2-4 نسبة امتزلز الصوديومج)

تُعد نسبة امتزاز الصوديوم ( SAR ) من أهم الخواص الهيدروكيميائية لمياه الري لتقيم مشكلة الترشيح للتربة التي تتتج عندما تكون نسبة الصوديوم في مياه الري أكثر من نركيز الكالسيوم زائداً المغنسيوم بنسبة (3:1) التي تسبب تشتت التربة ( Ayres and westcot,1985) • 


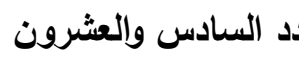

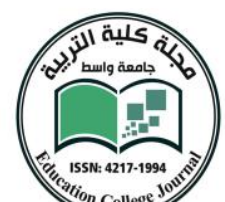

arion College 3

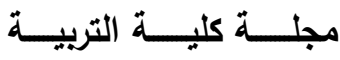

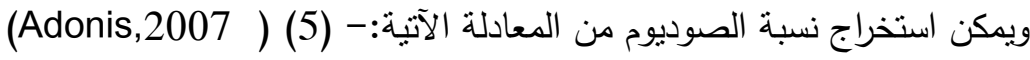

$S A R=\frac{N a}{\sqrt{\frac{C a+M g}{2}}}$

إذ يعبر عن الآيونات كافة ( epm/ L)

فإذا كانت القيمة (10>) فإنها من النوع الممتاز لأغراض الري ـ أما إذا كانت قيمها تقع ما بين (10)

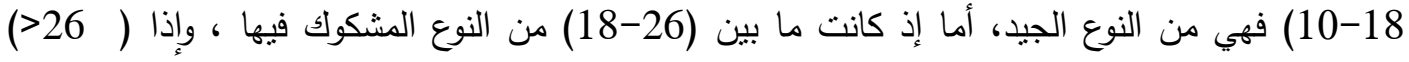

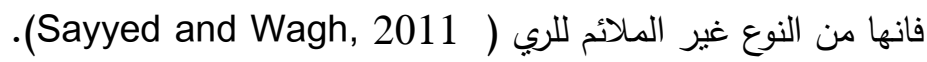

ومِن خلال جدول (6) نلاحظ أن قيم نسبة إمنزاز الصوديوم في منطقة الدراسة تقع قيمها ما بين

(5.25 - 2.52) وطبقاً للمعايير الموجودة تبين أن جميع نتائج العينات تقع ضمن الفئة المتازة لأغراض

جدول ( 6 ) ملائمة المياه الجوفية للري على اساس القيم المدخلة 2016

\begin{tabular}{|c|c|c|c|c|c|c|}
\hline & $\mathbf{Y}$ & $\mathbf{X}$ & $\mathbf{S A R}$ & $\mathbf{N a \%}$ & Gibbs-1 & Gibbs-11 \\
\hline S1 & & & & & & \\
\hline S2 & 33.0933 & 45.06901 & 5.25 & 28.8 & 0.89 & 0.54 \\
\hline S3 & 32.82756 & 45.10552 & 4.68 & 27 & 0.91 & 0.46 \\
\hline S4 & 32.92493 & 45.04263 & 4.1 & 24.8 & 0.92 & 0.46 \\
\hline S5 & 33.11561 & 44.87224 & 3.85 & 36.4 & 0.73 & 0.65 \\
\hline S6 & 33.06287 & 45.21303 & 4.05 & 26.5 & 0.89 & 0.59 \\
\hline S7 & 32.92087 & 45.4524 & 3.91 & 25.2 & 0.9 & 0.52 \\
\hline S8 & 33.01215 & 45.49297 & 4.55 & 35.1 & 0.89 & 0.54 \\
\hline S9 & 33.02433 & 45.353 & 3.05 & 24.2 & 0.89 & 0.44 \\
\hline
\end{tabular}


العــــــــد السادس والعشرون

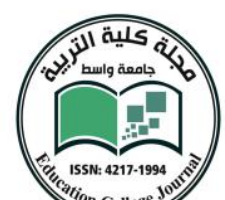

\begin{tabular}{|l|l|l|l|l|l|l|}
\hline S10 & 32.78699 & 45.33069 & 4.67 & 26.2 & 0.9 & 0.5 \\
\hline S11 & 33.03041 & 44.96352 & 2.52 & 31.5 & 0.71 & 0.49 \\
\hline S12 & 32.91276 & 45.29823 & 4.29 & 25.6 & 0.91 & 0.51 \\
\hline
\end{tabular}

(Aquachem v.4), المصدر :من عمل الباحث: بالاعتماد على :برنامج

\section{( Na\% (النسبة (المستوية للصوديوم (2-2-4)}

يُعد تركيز الصوديوم أمراً مهماً في تصنيف المياه الجوفية لأغراض الري لأنه بتفاعل مع التربة ، الأمر الذي يؤدي إلى إنسداد جزيئاتها مما يقلل من نفاذيتها ( Faris.2007) وقد عُدت النسبة ( 60\%)

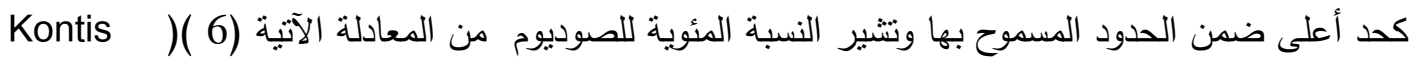
( and Gaganis, 2012

$N a \%=\left(\frac{N a+K}{C a+M g+N a+K}\right) \times 100$

$$
\text { إذ يعبر عن الآيونات كافة ( epm/L) }
$$

إن النسبة المئوية للصوديوم (Na\%) من منطقة الدراسة تتحصر قيمها مابين (36.4 - 24.2 ) كما في جدول (6).وكما نلاحظ أن في جدول ( 7 ) أن جميع العينات تقع ضمن الصفة الجيدة لأغراض الري. 
العــــــــد السادس والعشرون

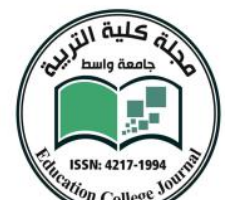

جدول ( 7 ) ) Na \% Nilcox, 1959 ) مينيف مياه الري وفقاً للنسبة المئوية )

\begin{tabular}{|c|c|c|c|c|}
\hline $\mathrm{Na} \%$ & $\begin{array}{c}\text { فئة المياه } \\
\text { water class }\end{array}$ & النسبة المئوبة & القيم الدنيا للنسبة & القيُم العليا للنسبة \\
\hline $20>$ & مدتازة & - & \multirow{5}{*}{24.2} & \multirow{5}{*}{36.4} \\
\hline $20-40$ & جيدة & 100 & & \\
\hline $40-60$ & مسموح بها & - & & \\
\hline $60-80$ & مشكوك بها & - & & \\
\hline $80<$ & غير ملائمة & - & & \\
\hline
\end{tabular}

المصدر: من عمل الباحث اعتمادا على جدول(6)

(Richards Digram .1954 ) مخطط ريتشارد

تم رسم قيم نسبة إمنزاز الصوديوم (SAR) والتوصيلة الكهربائية (Ec) لكل عينات المياه الجوفية ولجميع الآبار على مخطط ريتشارد(Richards Digran) ويبين الثكل (4) والجدول ( 8 ). أن جميع عينات المياه مصنفة إلى اربعة فئات فبالنسبة للآبار (S8-S9) تكون ملاعمتها من جيدة الى ممتازة اما الابار (S3-S4-S7-S10-S11) فإنها نكون ذات ملوحة مشكوك فيها وقلوية ممتازة، أما بقية الآبار فأنها تكون ملاعمتها ذات ملوحة مشكوك فيها وقلوية ممتازة الى جيدة وهي الآبار (S6-S2-S1-S12) ومن خلال ذلك نلاحظ أن ارتفاع الملوحة هو سبب إنخفاض مناسيب المياه في الأمطار مما أدى إلى زيادة

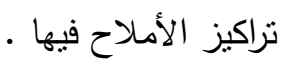



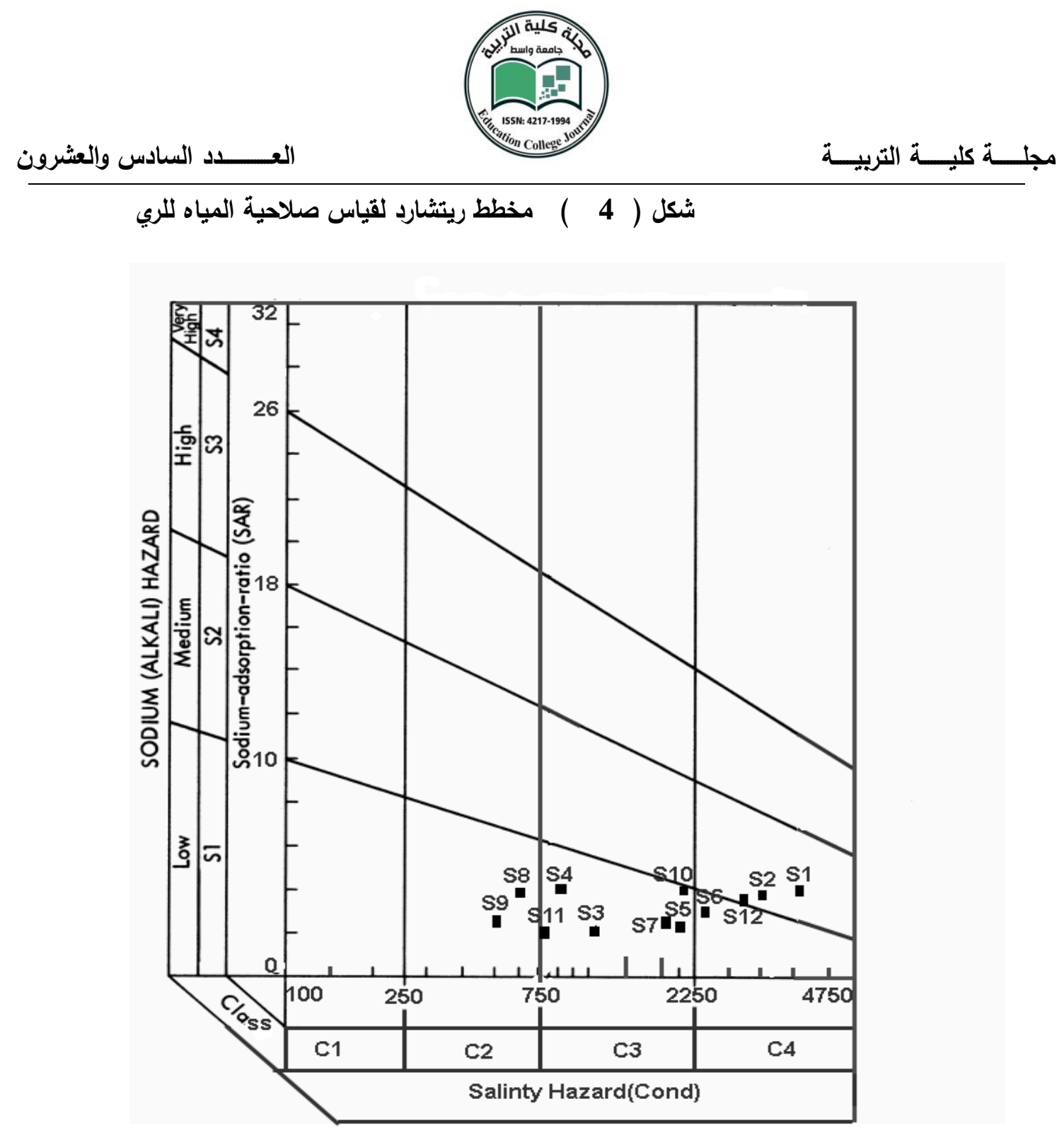

(Aquachem v.4) المصدر :من عمل الباحث: بالاعتماد على :برنامج) 
جدول ( 8 ) ) تصنيف مياه الري طبقآ لمخطط ريتشارد (1954 Richardi)

\begin{tabular}{|c|c|c|c|c|}
\hline \multirow{2}{*}{ الفئة } & \multirow{2}{*}{ وصف المياه } & \multicolumn{2}{|c|}{ التسبة المئوية } & \multirow{2}{*}{ Suilability الملائمة } \\
\hline & & 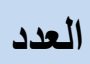 & $\%$ & \\
\hline C2 - S1 & ملوحة منتوسطة وخطر & 2 & 16.7 & جيدة الى ممتازة \\
\hline C3-S1 & ملوحة عالية وخطر & 6 & 50 & ملوحة مسموح بها وقلوية ممنازة \\
\hline C4 - S1 & ملوحة عالية جدا & 1 & 8.3 & ملوحة مشكوك فيها وقلوية \\
\hline C4 - S2 & ملوحة عالية جدا & 3 & 25 & مشكوك فيها الى جيدة \\
\hline
\end{tabular}

\section{4-2-4 التوزيع المكاني للخصائص النوعية}

للتساقط المطري أهمية كبيرة بالنسبة لخصائص المياه الجوفية فهو يحمل الغازات والمادة الدقائقية من الغلاف الجوي ومع التقاء قطرات المطر بسطح الارض فإنها تذيب جزء من مكونات الأرض لتحملها مع اتجاه حركتها إلى المناطق المنخفضة،أما المياه المترشحة فسوف تؤدي إلى تغيرات كيميائية على طول عمود التربة، فبذلك فإن خواص المياه الجوفية سوف تمثل حصيلة التفاعل المنبادل مع الصخور والتربة ومجرى الرواسب والماء.(خطاب،2006). ولغرض معرفة الوضع الهيدروجيوكيميائي لمياه منطقة الدراسة وطبيعة توزيع هذه الصفات تم رسم خرائط وأشكال بيانية لهذه الصفات.

نلاحظ من خلال توزيع قيم التوصيلة الكهربائية (Ec) إنخفاض قيمها في المناطق الثمالية الثرقية

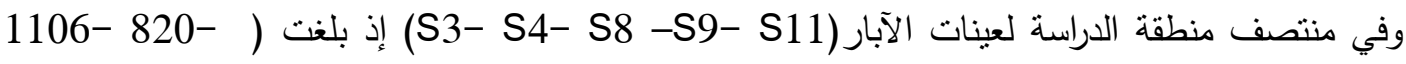
790 -558 -690) ملغرام/لتز على التوالي.وتنزايد قيمها في المناطق الثمالية والثمالية الغربية والمناطق الجنوبية الثرقية ـ كما في خريطة (5 ) ويعزى سبب ذلك إلى زيادة سمك الطبقات الجبسية فضلاً عن إتجاه 
العـــــــد السادس والعشرون

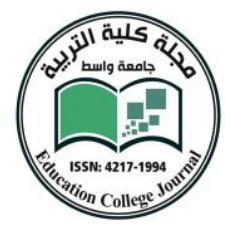

حركة المياه الجوفية من المناطق الثمالية والثمالية الثرقية،كما نلاحظ في شكل (5) التحليل الإحصائي أن ما نسبته ( 58\%) من ألمواقع تجاوزت المعدل. وأن وجود وارتفاع قيم آيون الكبريتات في المياه الجوفية كما في خربطة ( 6 ) جعل منه المسيطر الأكبر على توزيع قيم الإيصالية الكهربائية والمجموع الكلي للأملاح الذائبة كما في خريطة وشكل( 7 ) وإن إرتفاع قيم (TDS) ينتج عن تحلل المواد العضوية والأسمدة المستخدمة في الزراعة.أما في شكل (6) نلاحظ ما نسبته(66.6\%) تجاوزت المعدل .كما نلاحظ زيادة تركيز آيون الكبريتات مع كل من عنصري الصوديوم (Na) والمغنيسيوم (Mg) في أغلب مناطق منطقة الدراسة، ينظر الخربطة (8).أما شكل(8) نلاحظ ما نسبته(58.3\%) تجاوز المعدل الطبيعي.

أما توزيع عنصر الكالسيوم (Ca) ينقسم الى قسمين كما في خريطة (9) قسم يقع في الجزء الثمالي الغربي الواطئة التركيز المتمنلة بعينات الآبار (S3- S5- S11) والقسم الاخر في الجزء الثمالي والثمالي الثرقي المتمثلة بباقي العينات. إذ أن سرعة ذوبان طبقات الجبس نسبة إلى باقي الصخور تؤدي

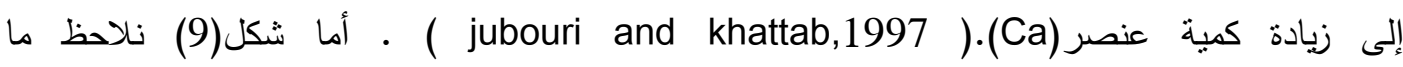
نسبته (66.6\%) تجاوز المعدل.

أما بالنسبة للدالة الحامضية (PH) نلاحظ بأن جميع العينات تكون قاعدية وعند مقارنتها بالمحددات العالمية والعراقية نلاحظ بأن قيمها تقل في مواقع العينات (S10 - S4 ) إذ بلغت (8.4 -8.4 ) ملغرام/لتر على التوالي، وتتوزع في الجزء الجنوبي والجنوب الثرقي من منطقة الدراسة..أما بقية العينات فإن قيمها تزداد وتتوزع في أغلب مناطق منطقة الدراسة. كما في خريطة (10)ز وما يقارب نسبته • (12\%)

إن زيادة قيمة (PH) و انخفاضها في الماء يؤثز على توازن الكاربونات والبيكاربونات وينتج عن ذلك تحرير غاز ثاني اوكسيد الكاربون ويؤدي بعد ذلك إلى زيادة قابلية الماء على الإذابة ومن ثم إلى زيادة نركيز

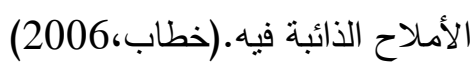

أما تأثير قيمة (PH) على حركة بعض العناصر في المياه الجوفية يظهر تقريباً في التوزيع شبه الدائري لآيون البوتاسيوم خريطة (11) ،والصوديوم خريطة (12) والكلوريدات خريطة (13) وبصورة واضحة على توزيع البكاربونات خريطة (14)إذ يظهر تزايد البيكاربونات في المناطق الثمالية والثمالية الغربية 
وجنوب شرق منطقة الدراسة. أما بالنسبة لعنصر (TH) العسرة نلاحظ من خلال خريطة (15) إن قيمها تنزايد في المناطق الثرقية والجنوبية الثرقية والثمالية والثمالية الغربية،أما في المناطق الثمالية الشرقية فإن قيمها تتناقص لعينات المياه (S11 - S9- S11) وسبب ارتفاع نسبته هو وجود أملاح الكبريتات وكلوريدات الصوديوم والكالسيوم الذائبة في الماء التي تحتويها منطقة الدراسة.وما يقارب نسبته ( - 12 - 75 - 66.6 (15)) 66.6 - 12 \% للأثكال 


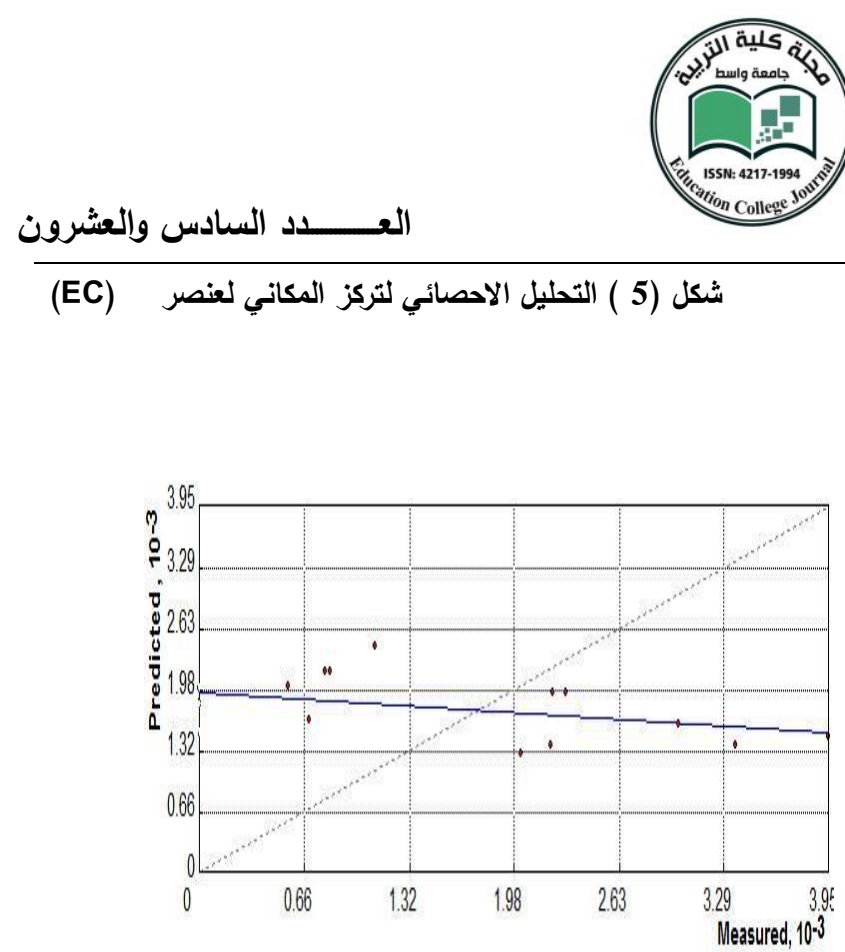

المصدر :الباحث بالاعتماد على جدول (3 )

شكل( 6) التحليل الاحصائي لتركز المكاني لعنص (SO4)

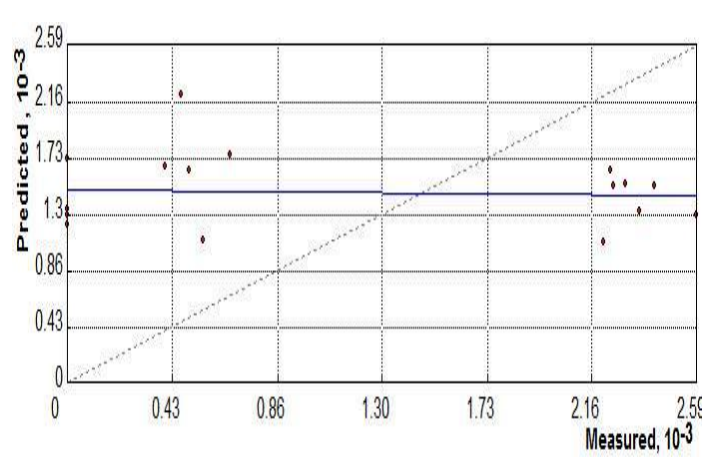

المصدر :الباحث بالاعتماد على جدول (3)

\section{مجلـــة كليـــة التربيـــة}

خريطة ( 5 )

لموقع العينات

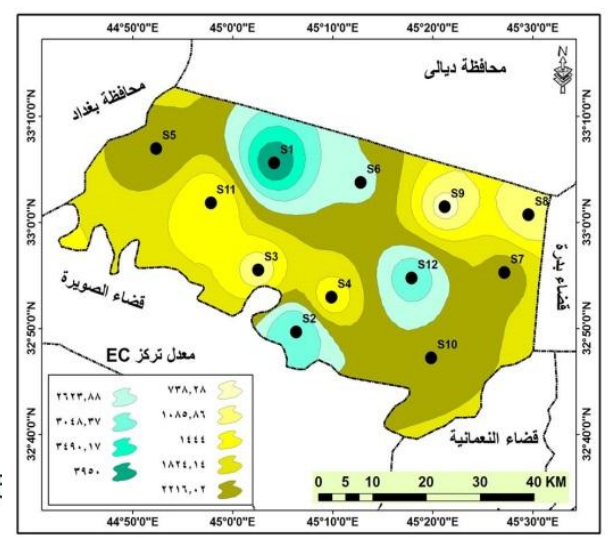

المصدر :الباحث بالاعتماد على جدول ( 3 )

خريطة ( 6 )

لموقع العينات

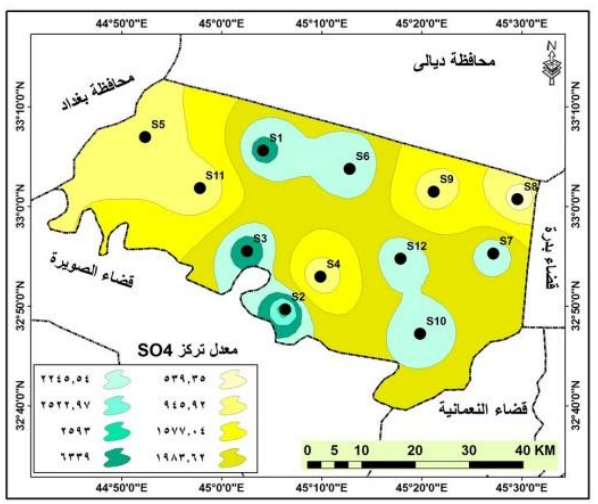

المصدر :الباحث بالاعتماد على جدول (3) 


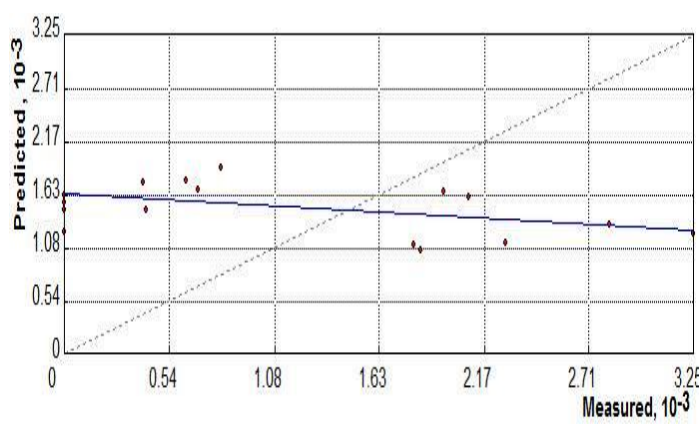

المصدر :الباحث بالاعتماد على جدول (3 )

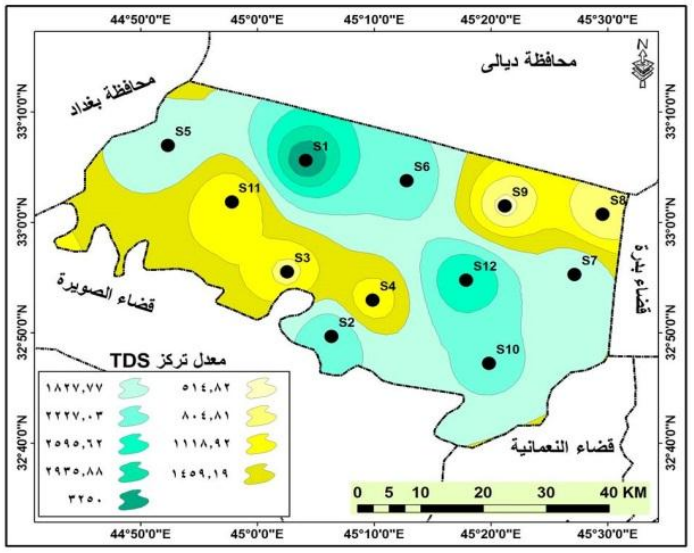

المصدر :الباحث بالاعتماد على جدول (3 )

لموقع العينات

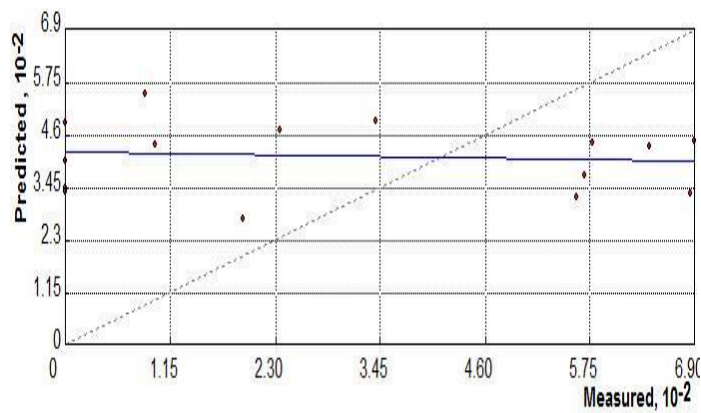

المصدر :الباحث بالاعتماد على جدول (3 )

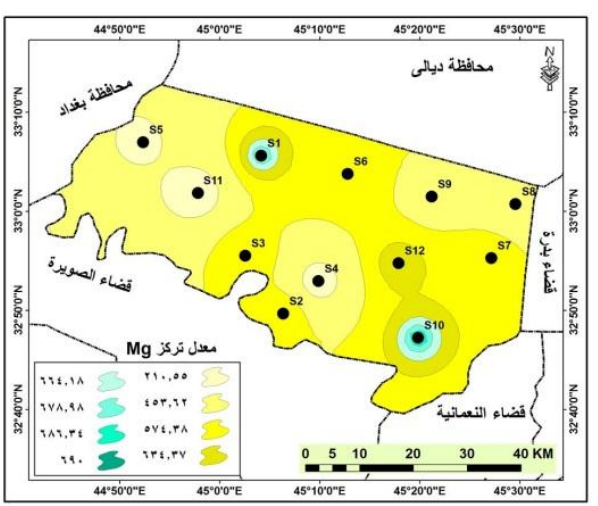

المصدر :الباحث بالاعتماد على جدول (3 ) 


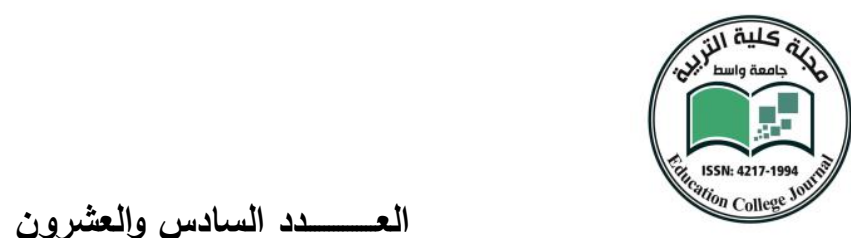

العـــــــدد السادس والعشرون

مجلــــة كليـــة التربيـــة

شكل (9 ) التحليل الاحصائي لتركز المكاني لعنصر (Ca)

خريطة ( 9 )

لموقع العينات

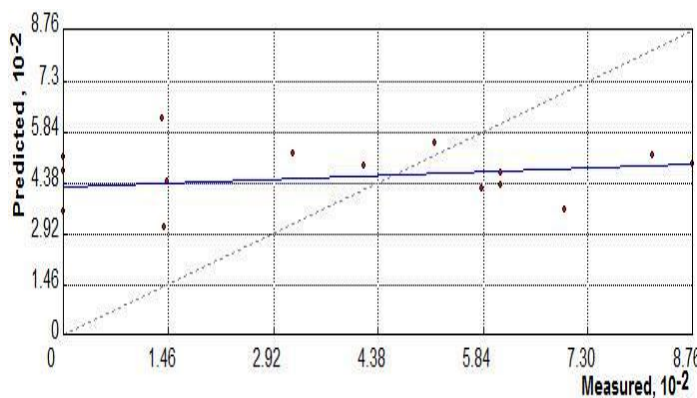

المصدر :الباحث بالاعتماد على جدول (3 )

شكل (10 ) التحليل الاحصائي لتركز المكاني لعنصر (PH)

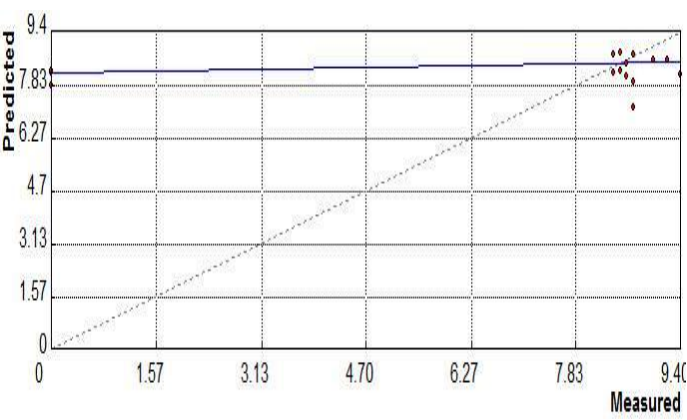

المصدر :الباحث بالاعتماد على جدول (3 )

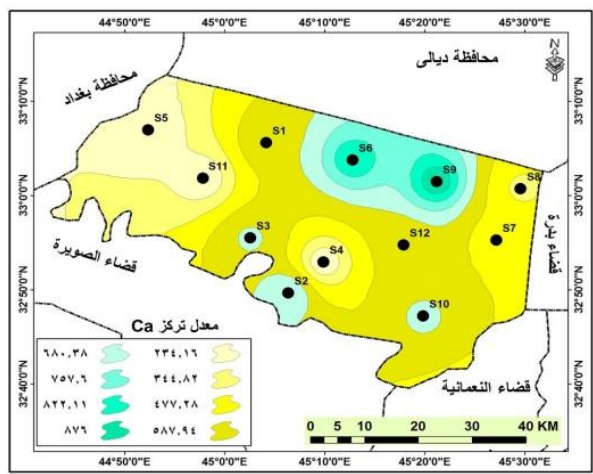

المصدر :الباحث بالاعتماد على جدول (3 )

خريطة ( 10 )

لموقع العينات

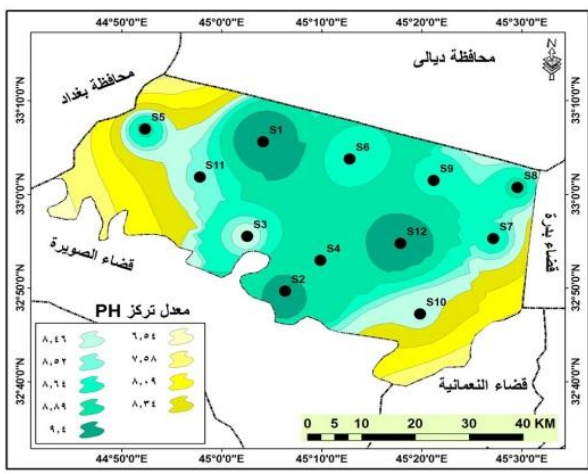

المصدر :الباحث بالاعتماد على جدول (3 ) 


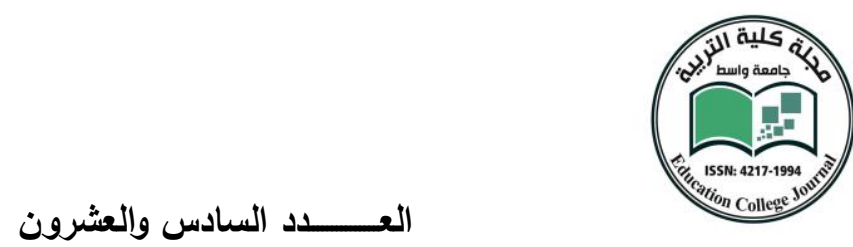

شكل (11 ) التحليل الاحصائي لتركز المكاني لعنصر (K)

مجلــــة كليـــــة التربيـــــة

خريطة ( 11 )

لموقع العينات

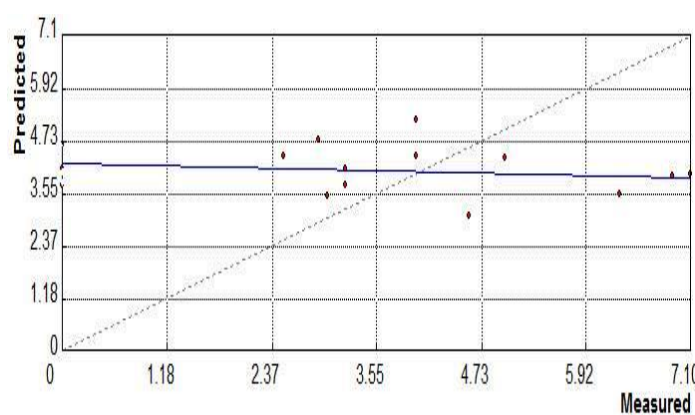

المصدر :الباحث بالاعتماد على جدول (3)

شكل (12 ) التحليل الاحصائي لتركز المكاني لعنصر (Na)

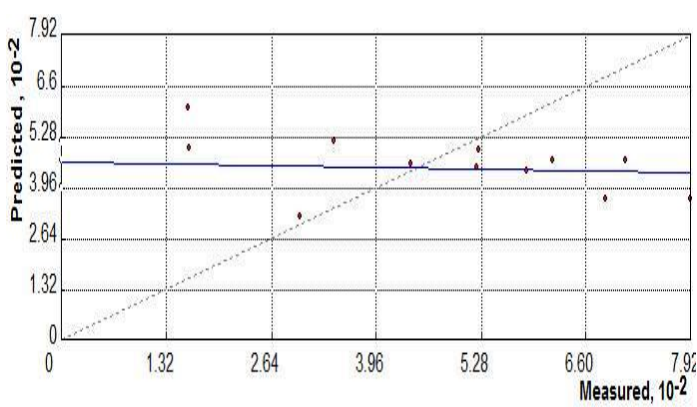

المصدر :الباحث بالاعتماد على جدول (3 )

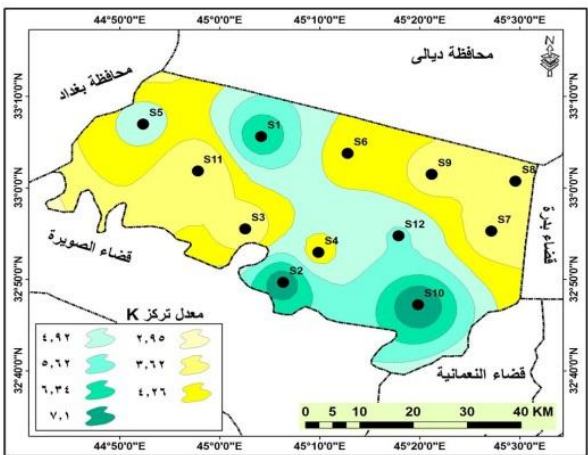

المصدر :الباحث بالاعتماد على جدول (3 )

خريطة (12)

لموقع العينات

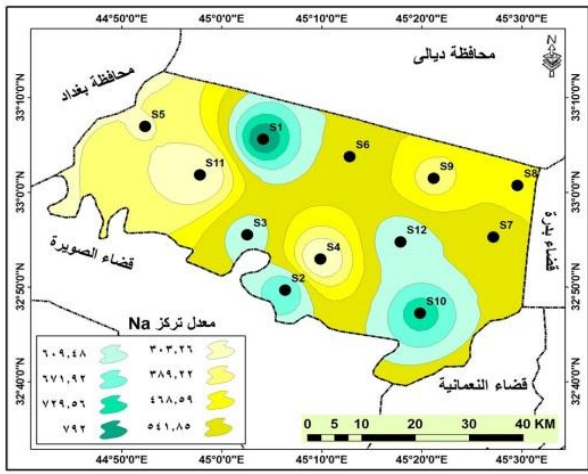

المصدر :الباحث بالاعتماد على جدول (3 ) 


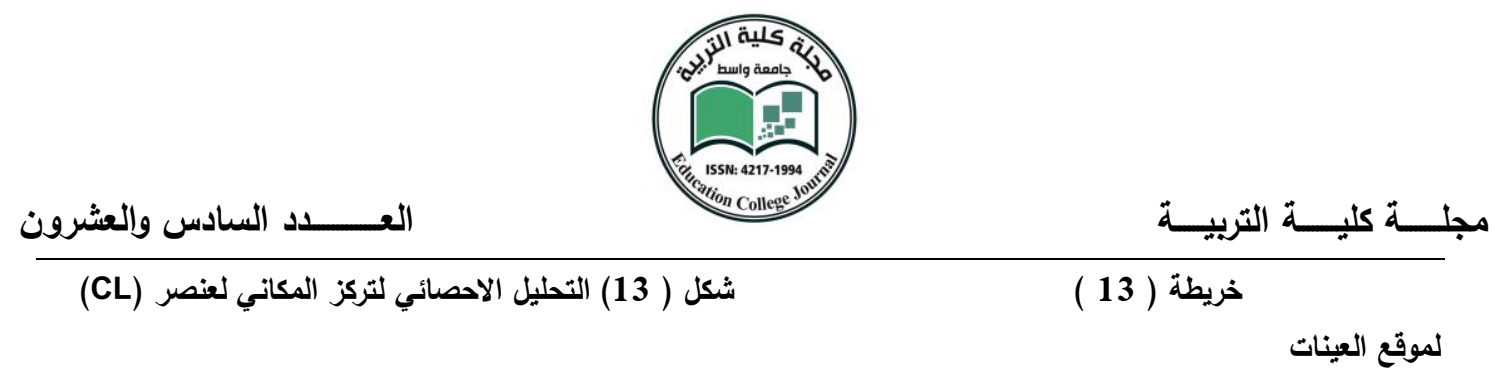

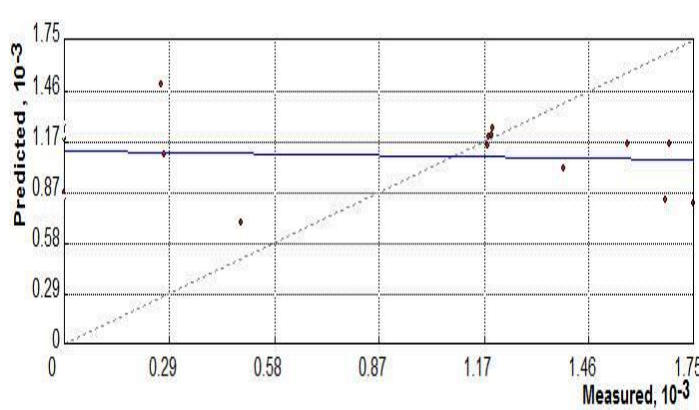

المصدر :الباحث بالاعتماد على جدول (3)

شكل (14 ) التحليل الاحصائي لتركز المكاني لعنصر (HCO3)

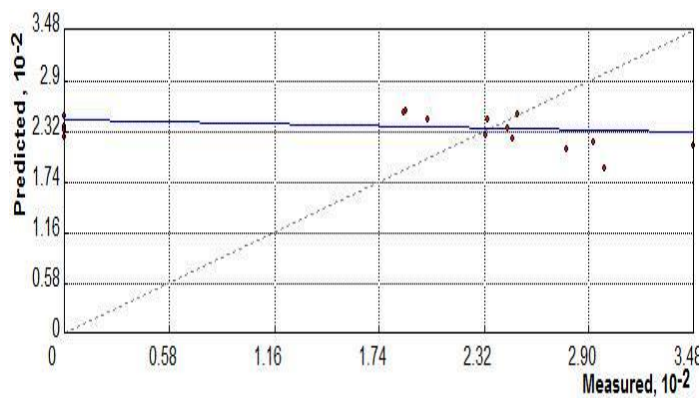

المصدر :الباحث بالاعتماد على جدول (3 )

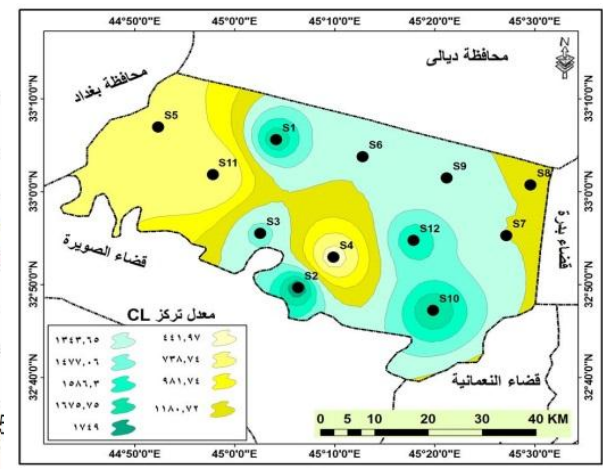

المصدر :الباحث بالاعتماد على جدول (3 )

خريطة ( 14 )

لموقع العينات

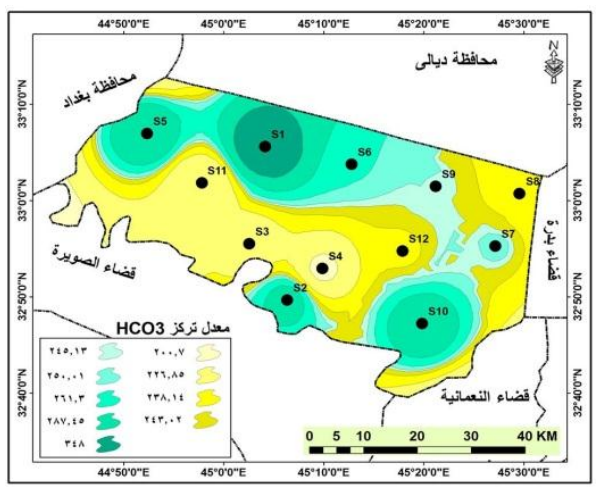

المصدر :الباحث بالاعتماد على جدول (3 ) 


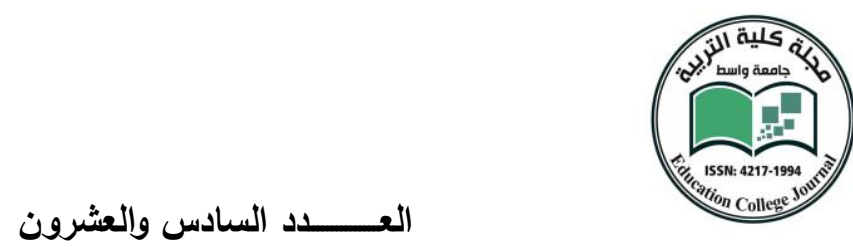

شكل (15 ) التحليل الاحصائي لتركز المكاني لعنصر (TH)

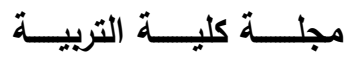

$$
\text { شكل (15 ) النحايل الاحصائي لتركز المكاني لعنصر (TH) }
$$

خريطة ( 15 )

لموقع العينات

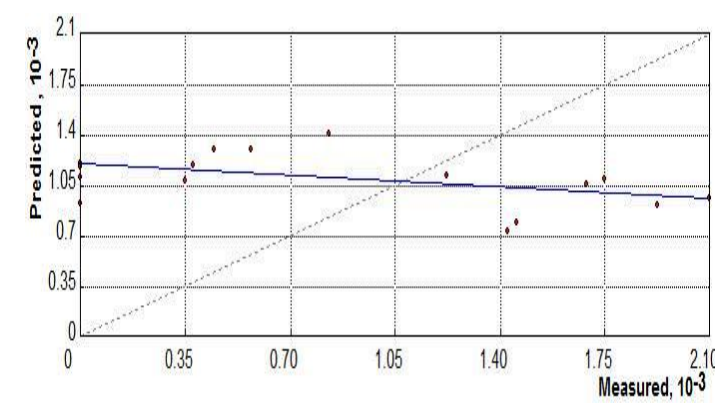

المصدر :الباحث بالاعتماد على جدول ( 3 )

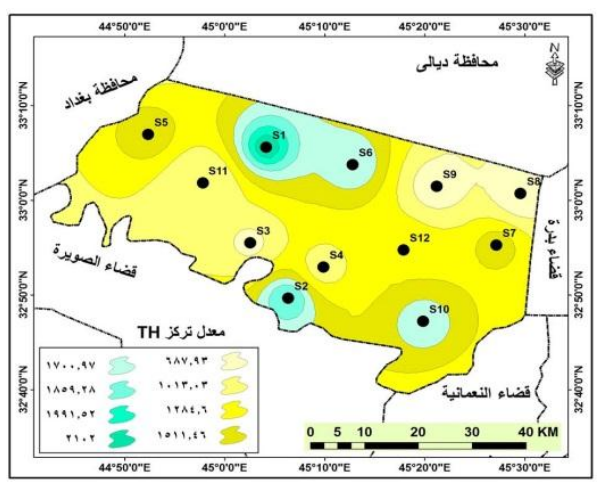

المصدر :الباحث بالاعتماد على جدول (3 )

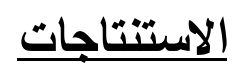

اظهرت الدراسة الهيدروجيوكيميائية للمياه الجوفية في قضاء العزيزية، متمثلة بالمسح الميداني

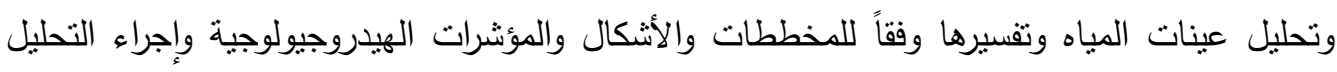

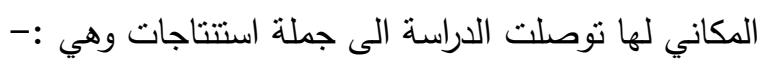

1- جميع النتائج هي من نوع (Sulfat water type ) مع تغير الايونات الموجبة والسالبة حيث

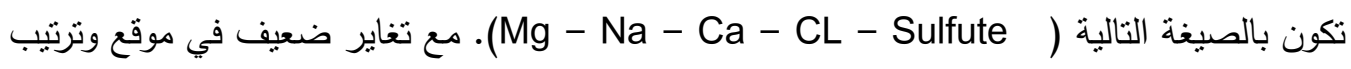

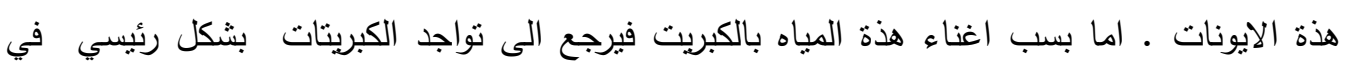
المنطقة على شكل معدن الجبس.

2- صنفت هذه المباه الى خمسة اصناف كلاً حسب تنتابهها من حيث المكونات الكيميائية .

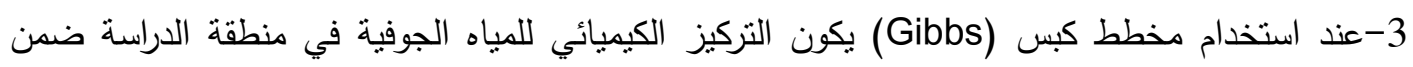

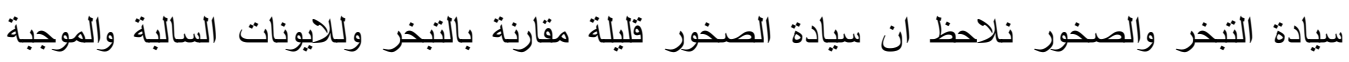

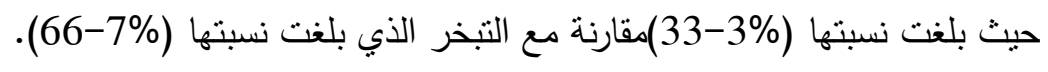


العــــــد السادس والعشرون

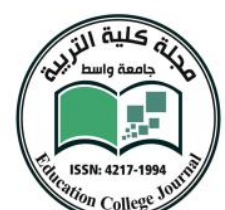

4- عند مقارنة نتائج التحاليل الكيميائي مع المواصفة العالمية والعراقية تبين ان مياه منطقة الدراسة لاتصلح

لشرب الانسان لزيادة اغلب تراكيز العناصر للحدود المسموح بها.

5- نلاحظ ان قيم نسبة امتزاز الصوديوم(SAR) في منطقة الدراسة تقع قيمتها ما بين (5.25 - 2.52) وطبقآ للمعايير الموجودة تبين ان جميع نتائج العينات تقع ضمن الفئة المتازة لاغراض الري.

6- ان النسبة المئوية للصوديوم (Na\%) من منطقة الدراسة تتحصر قيمها مابين (36.4 - 24.2 ) وبذلك نلاحظ ان جميع العينات تقع ضمن الصفة الجيدة لاغراض الري.

7-عند استخدام مخطط ريتشارد) تنين ان جميع عينات المياه مصنفة الى اربعة فئات S3-S4-S7-S10-) فبالنسبة لكبار (S8-S9) تكون ملائمتها من جيدة الى ممتازة اما الابار

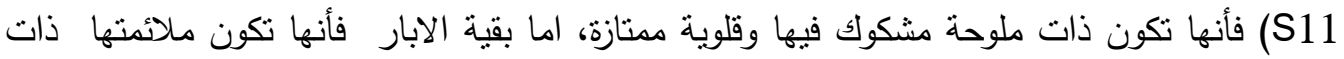
ملوحة مشكوك فيها وقلوية ممتازة الى جيدة وهي الابار (S6-S2-S1-S12) ومن خلال ذلك نلاحظ ان ارتفاع الملوحة هو سبب انخفاض مناسيب المياه في الامطار مما ادى الى زيادة تراكيز الاملاح فيها

8- تم رسم خرائط واشكال بيانية لهذه العناصر وطبيعة توزيعها فتبين من خلال توزيع قيم التوصيلة الكهربائية (Ec) انخفاض قيمها في المناطق الثمالية الشرقية وفي منتصف منطقة الدراسة،ويعزى سبب ذلك الى زيادة سمك الطبقات الجبسية. وان وجود وارتفاع قيم ايون الكبريتات في المياه الجوفية كما جعل منه المسيطر الاكبر على توزيع قيم الايصالية الكهربائية والمجموع الكلي للاملاح الذائبة كما نلاحظ زيادة نركيز ايون الكبريتات مع كل من عنصري الصوديوم (Na) والمغنيسيوم (Mg) في اغلب مناطق منطقة الدراسة، اما توزيع عنصر الكالسيوم (Ca) ينقسم الى قسمين قسم يقع في الجزء الثمالي الغربي الواطئة التركيز المتمتلة بعينات الابار (S3- S5- S11 ) والقسم الأخر في الجزء الثمالي والثمالي الثرقي المتمثلة بباقي العينات، أما بالنسبة للالة الحامضية(PH) نلاحظ بأن جميع العينات تكون قاعدية 


$$
\text { بناءً على النتائج التي توصلت لها الدراسة، تم تسجيل مجموعة من التوصيات وهي:- }
$$

1-ضرورة اجراء دراسات تفصيلية عن امكانية استثمار المياه الجوفية في منطقة الدراسة ،ولاسَيَّما في المناطق الشرقية من خلال حفر الابار المائية خاصة وأنَّ تلك المنطقة ملائمة جداً للاسنثمار الزراعي.

2-إجراء تحاليل دورية لمياه الآبار المحفورة في منطقة الدراسة لغرض معرفة مقدار التغير في التركيب الكيميائي لهذه المياه بمرور الزمن.

3-اجراء تحليلات كيميائية تفصيلية لكل العناصر الثانوية والنادرة والسامة لمياه الآبار الواقعة في تلك المنطقة.

4- عدم استخدام مياه الآبار التي تتركز فيها بعض العناصر النادرة لاغراض ارواء الحيوانات او الزراعة، والتي بالامكان انتقالها الى الانسان عبر السلسلة الغذائية. 


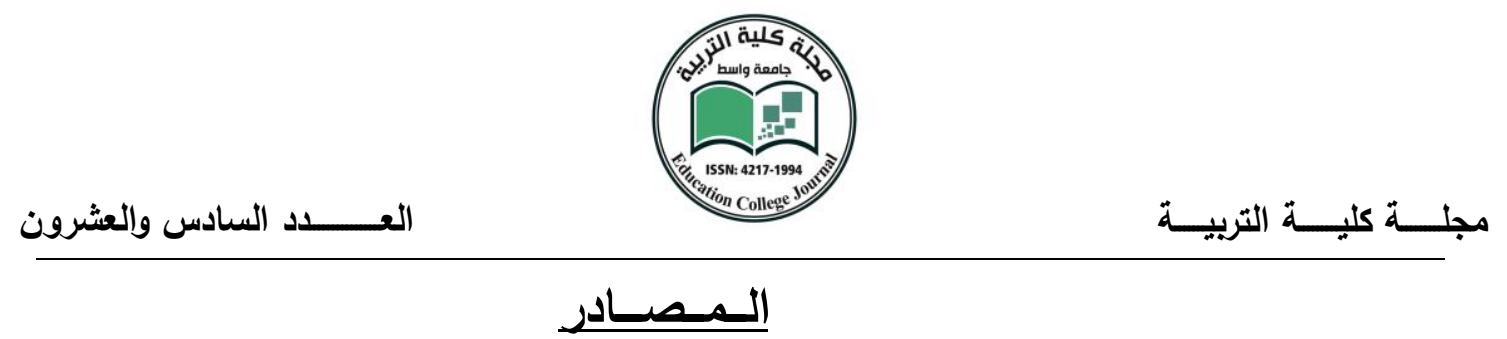

\section{المصادر العريبة}

1-الجبوري حاتم خضير والبصراوي، نصير حسن (2001). دراسة هيدرولوجية وهيدروكيميائية منطقة لوحة النجف، الشركة

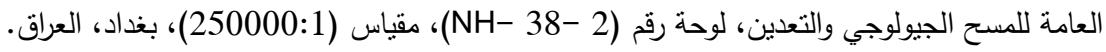

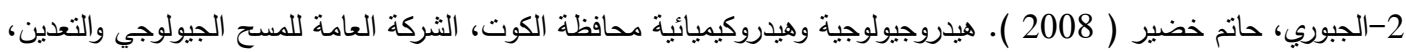
لوحة رقم (15-38-3H)، مقياس (250000/1)، رقم التقرير (2506)، (3069)، بغداد العراق.

شويرات جنوب 3-خطاب، محمد فوزي (2006 ). دراسة الخصائص النوعية للمياه الجوفية لمنطقة الموصل، مجلة تكريت للعلوم الصرفة، المجلد (11)، العدد (1).

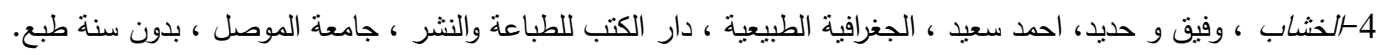
5- رسن، واخرون (2015) ، جغرافية محفظة واسط، دار الاعصار ، بغداد، العراق.

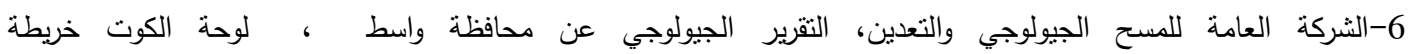
$.2008 \cdot 250000 / 1$ 7-القره غولي ،(2014) ، التحليل المكاني للمياه الجوفية واستخداماتها في محافظة القادسية، اطروحة دكتوراه (غير منشورة)،قم الجغرافية، كلية التربية، الجامعة المستتصرية.

8-المسعودي ،(2013) ، الخصائص البيئية لمياه نهر دجلة في محافظة واسط، اطروحة دكتوراه (غير منشورة)،قسم الجغرافية، كلية التربية، الجامعة المستتصرية. 9-النقاش، عدنان باقر والصحاف، محمد علي (1989). الجيمورفولوجي، كلية التربية، جامعة بغداد. 10-الهيأة العامة للمساحة،خريطة العراق الادارية، مقياس 1 / / 1 /

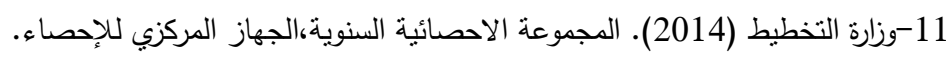
12-وزارة النقل والمواصلات، الهيأة العامة للأنواء الجوية والرصد الزلزالي العراقية، بيانات مناخية لمحطة (العزيزية)، قسم المناخ لإحكاء (بيانات غير منشورة). 13-وزارة العلوم والتكنولوجيا، دائرة البيئة والمياه ، مختبر اعادة تدوير المياه . . 
1. Ayers, R.S., and Westcot, W.D, (1985). Water Quality for Agriculture, Irrigation and drainage paper (29 Rev.1). FAO Rome Italy.

2. Adonis, S., ( 2007). The hydrochemical characteristics of ground water in the incomatiestuary, Faculty of Science, University of the Western Cape.

3. AL-Jubouri,Z.A.and Khattab,S.L.A.(1997).The dissolution of calcium sulphate rocks below the foundation of large hydraulics structure.Raf.Jou.Sci.,Vol.8.

4. - Deshpande,S.M and Aher,K.R.,(2012) .Evaluation of Ground water Quality and its Suitability for Drinking and Agriculture Use in Parts of Vaijapur ,District Aurangabad ,MS,India .Research Journal of Chemical Sciences .Val.2.

5. Faris,A.A.,(2009). Application Of Remote Sensing And Gis Techniques For The Assessment Of Groundwater In Kandukuru Vagu Basin, Nalgonda District, A.P. Ph.D. Thesis (Unpublished), Osmania University, Hyderabad, India.

6. Gibbs, (1970). Mechanisms controlling world water chemistry, Science, 170, 1088.

7. IRS, (1996). Drinking Water Standards, Central Organization for Standardization and Quality Control, Min. of Planning .

8. Kontis,E.E., and Gaganis.P., ( 2012), Hydrochemical Characteristics and Groundwater Quality In The Island Of Lesvos, Greece, Global NEST Journal, Vol 14, Printed in Greece.

9. -Ritchard, L.A., (1954). Diagnosis and Improvement of Saline and Alkali S. Doils, Agri Handbook 60, U.S.dep. Agric., Washington D.C.

10.Sayyed,M.R.G and Wagh, G.S.,(2011).An assessment of ground water quality for agricultural use: a case study from solid waste disposal site SE of Pune, India. proceedings of the International Academy of Ecology and Environmental sciences .

11. Sehgal, J.L., Mohammed, M.A,AL-Johar. T, ALLewy. R, (1983). The Soil of The Middle Tigris Project (MESOPOTAMIANPLAIN)For Land-use Planning, Stat Organization For Soil\& Land Reclamation, BAGHDAD(IRAQ).

12. Wilcox, L. V., 1955. Classification and Uses of Irrigation Water, USDA, Circular, No. 969, Washington, D.C.

13. WHO, (2011). Guidelines for drinking-water quality - 4th Edition.

14.WHO., (1996). Water Quality Monitoring -A practical Guide to the Design and implementation of Freshwater Quality studies and Monitoring Programmers, Edited by Jamie Bartram and Richard Balance.

15-Xing,L., Guo, H., and Zhan, Y,. (2013)ground water hydrochemical. characteristics and processes along flow paths in the North China Plain. Journal of Asian Earth Sciences . 